\title{
HCOOH measurements from space: TES retrieval algorithm and observed global distribution
}

\author{
K. E. Cady-Pereira ${ }^{1}$, S. Chaliyakunnel ${ }^{2}$, M. W. Shephard ${ }^{3}$, D. B. Millet $^{2}$, M. Luo ${ }^{4}$, and K. C. Wells ${ }^{2}$ \\ ${ }^{1}$ Atmospheric and Environmental Research, Inc., Lexington, Massachusetts, USA \\ ${ }^{2}$ University of Minnesota, Minneapolis-St. Paul, Minnesota, USA \\ ${ }^{3}$ Environment Canada, Toronto, Ontario, Canada \\ ${ }^{4}$ Jet Propulsion Laboratory, California Institute of Technology, Pasadena, California, USA \\ Correspondence to: K. E. Cady-Pereira (cadyp@aer.com)
}

Received: 16 January 2014 - Published in Atmos. Meas. Tech. Discuss.: 28 February 2014

Revised: 12 June 2014 - Accepted: 23 June 2014 - Published: 30 July 2014

\begin{abstract}
Presented is a detailed description of the TES (Tropospheric Emission Spectrometer)-Aura satellite formic acid $(\mathrm{HCOOH})$ retrieval algorithm and initial results quantifying the global distribution of tropospheric $\mathrm{HCOOH}$. The retrieval strategy, including the optimal estimation methodology, spectral microwindows, a priori constraints, and initial guess information, are provided. A comprehensive error and sensitivity analysis is performed in order to characterize the retrieval performance, degrees of freedom for signal, vertical resolution, and limits of detection. These results show that the TES $\mathrm{HCOOH}$ retrievals (i) typically provide at best 1.0 pieces of information; (ii) have the most vertical sensitivity in the range from 900 to $600 \mathrm{hPa}$ with $\sim 2 \mathrm{~km}$ vertical resolution; (iii) require at least $0.5 \mathrm{ppbv}$ (parts per billion by volume) of $\mathrm{HCOOH}$ for detection if thermal contrast is greater than $5 \mathrm{~K}$, and higher concentrations as thermal contrast decreases; and (iv) based on an ensemble of simulated retrievals, are unbiased with a standard deviation of $\pm 0.4 \mathrm{ppbv}$. The relative spatial distribution of tropospheric $\mathrm{HCOOH}$ derived from TES and its associated seasonality are broadly correlated with predictions from a state-ofthe-science chemical transport model (GEOS-Chem CTM). However, TES $\mathrm{HCOOH}$ is generally higher than is predicted by GEOS-Chem, and this is in agreement with recent work pointing to a large missing source of atmospheric $\mathrm{HCOOH}$. The model bias is especially pronounced in summertime and over biomass burning regions, implicating biogenic emissions and fires as key sources of the missing atmospheric $\mathrm{HCOOH}$ in the model.
\end{abstract}

\section{Introduction}

Formic acid $(\mathrm{HCOOH})$ plays an important role in tropospheric chemistry. It regulates $\mathrm{pH}$-dependent reactions in clouds (Keene and Galloway, 1988) and is one of the main sinks of in-cloud OH radicals (Jacob, 1986). Along with acetic acid it is a major contributor to the acidity of precipitation, especially in remote regions (Keene and Galloway, 1988; Andreae et al., 1988). Photochemical production is thought to be the largest global source of $\mathrm{HCOOH}$, with known precursors including isoprene, monoterpenes, other terminal alkenes (e.g., Neeb et al., 1997; Lee et al., 2006; Paulot et al., 2011), alkynes (Hatakeyama et al., 1986; Bohn et al., 1996), and possibly acetaldehyde (Andrews et al., 2012; Clubb et al., 2012). Primary sources of $\mathrm{HCOOH}$ include biomass and biofuel burning (e.g., Goode et al., 2000), biogenic emissions from plants and soils (e.g., Kesselmeier et al., 1998; Kuhn et al., 2002; Jardine et al., 2011; Sanhueza and Andreae, 1991), agriculture (e.g., Ngwabie et al., 2008), and urban emissions (e.g., Kawamura et al., 1985; Talbot et al., 1988).

$\mathrm{HCOOH}$ is removed from the atmosphere mainly through wet and dry deposition. Photochemical loss is relatively slow ( $\tau \sim 25$ days), so that any $\mathrm{HCOOH}$ formed or vented outside of the boundary layer can be transported for long distances in the free troposphere (Paulot et al., 2011). Irreversible uptake on dust can be significant under some conditions, but appears to be minor on a global scale (Hatch et al., 2007; Paulot et al., 2011). The overall atmospheric lifetime for $\mathrm{HCOOH}$ is estimated at 3-4 days (Stavrakou et al., 2012). 
The above $\mathrm{HCOOH}$ sources are poorly quantified, and recent work has revealed major inconsistencies between model predictions and observed $\mathrm{HCOOH}$ concentrations. Paulot et al. (2011) found that $\mathrm{HCOOH}$ levels predicted by the GEOS (Goddard Earth Observing System)-Chem chemical transport model (CTM) exhibited a persistent low bias relative to available ground-based and airborne observations. The comparisons implied a large missing secondary source of $\mathrm{HCOOH}$; proposed candidates to explain the modelmeasurement discrepancies included missing biogenic or biomass burning precursors, as well as organic aerosol oxidation. Stavrakou et al. (2012) also found evidence of a large model underestimate of atmospheric $\mathrm{HCOOH}$ on the basis of satellite measurements from the Infrared Atmospheric Sounding Interferometer (IASI), and attributed the discrepancy to a missing primary or secondary source from terrestrial vegetation.

The first spaceborne observations of atmospheric $\mathrm{HCOOH}$ were based on observations of biomass burning events from the Atmospheric Chemistry Experiment Fourier Transform Spectrometer (ACE-FTS) (Rinsland et al., 2006, 2007). The ACE-FTS makes solar occultation measurements using limbviewing geometry, and the resulting data are restricted to the upper troposphere and lower stratosphere. Another limb instrument, the MIPAS (Michelson Interferometer for Passive Atmospheric Sounding)-Envisat emission spectrometer, was used to examine the regional and seasonal variability of $\mathrm{HCOOH}$ at $10 \mathrm{~km}$, and revealed very strong seasonal cycles over southern Africa and Indonesia-Australia (Grutter et al., 2010). The IASI FTS instrument retrieves $\mathrm{HCOOH}$ in nadir viewing mode (Coheur et al., 2009), providing measurements of tropospheric $\mathrm{HCOOH}$ from upwelling thermal infrared radiances. Razavi et al. (2011) applied a simple and computationally efficient retrieval strategy (based on brightness temperature differences between a clear window and an $\mathrm{HCOOH}$ absorption feature) to invert the IASI observations into total column concentrations and provide a global picture of the distribution of atmospheric $\mathrm{HCOOH}$, albeit with large uncertainties. The present paper will describe the retrieval of $\mathrm{HCOOH}$ from global, high spectral resolution nadir Tropospheric Emission Spectrometer (TES) measurements, an FTS on NASA's Aura platform (Beer et al., 2001).

TES's high spectral resolution $\left(0.06 \mathrm{~cm}^{-1}\right)$, spatial resolution $\left(5 \times 8 \mathrm{~km}^{2}\right)$, good signal-to-noise ratio $(\mathrm{SNR})$ in the 1B2 band (920-1150 $\mathrm{cm}^{-1}$; Shephard et al., 2008), and radiometric stability (Connor et al., 2011) provide the capacity to measure atmospheric concentrations of several weakly absorbing species: ammonia (Shephard et al., 2011; Zhu et al., 2013; Pinder et al., 2011), methanol (Cady-Pereira et al., 2012; Wells et al., 2012, 2014), PAN (Payne et al., 2014), and $\mathrm{HCOOH}$, as is described in this paper. The high spectral resolution allows the use of spectral microwindows in the retrieval that both increase computational efficiency and reduce the impact of interfering species. Furthermore, Aura is in a sun-synchronous orbit with daytime and nighttime overpasses at 13:30 and 01:30 (mean local solar time). Since TES is a nadir-viewing thermal infrared instrument, the high thermal contrast between the surface and lower troposphere around the time of the early afternoon overpass translates to enhanced sensitivity to boundary layer $\mathrm{HCOOH}$.

The TES and IASI instruments share many characteristics but have different strengths. Both are FTS instruments in polar orbits and use the same spectral features to measure $\mathrm{HCOOH}$, albeit with different algorithms. IASI provides much greater temporal and spatial coverage, which allows more measurements to be averaged and thus reduces the impact of random errors. The TES daytime overpass time is closer to the peak in thermal contrast and its high spectral resolution eliminates contamination from the ammonia feature at $\sim 1103 \mathrm{~cm}^{-1}$, thus providing more sensitivity and reduced errors.

Combining the TES sensor capabilities with a rigorous global retrieval provides the opportunity to obtain global information on lower tropospheric $\mathrm{HCOOH}$ with greater accuracy than has been previously obtained. We present here a detailed description of the TES optimal estimation retrieval approach and strategy. The retrieval performance (i.e., sensitivity, error estimates) is evaluated in a simulation environment, and initial global TES retrievals (year 2009) are provided and compared against model output for the same year, in order to assess the degree to which the observed spatiotemporal variability in $\mathrm{HCOOH}$ is consistent or at odds with present scientific understanding of its sources and sinks.

\section{TES HCOOH retrieval algorithm}

\subsection{Retrieval methodology}

The TES HCOOH retrieval is based on an optimal estimation approach (Rodgers, 2000) that has been developed for TES observations of trace gases with weak atmospheric spectral signatures (Shephard et al., 2011; Cady-Pereira et al., 2012). The general retrieval methodology is described in the Appendix; in this section we present details specific to the retrieval of $\mathrm{HCOOH}$.

Infrared nadir retrievals of $\mathrm{HCOOH}$ are challenging due to the relatively weak top-of-atmosphere (TOA) radiance signal ( $\sim 1 \mathrm{~K}$ brightness temperature for an enhanced profile). In order to provide the most accurate atmospheric state for the $\mathrm{HCOOH}$ retrievals, atmospheric temperature, water vapor, ozone, methane, carbon dioxide, cloud optical depth and height, and surface temperature and emissivity are retrieved prior to HCOOH itself (JPL, 2006; Kulawik et al., 2006). The $\mathrm{HCOOH}$ retrieval is carried out next in a two-step process: first, a refinement of the surface temperature and emissivity retrieval is performed, and then the $\mathrm{HCOOH}$ retrieval is performed. Including the first step can significantly reduce the residuals in the $\mathrm{HCOOH}$ spectral region and leads to more stable HCOOH retrievals. Following Shephard et al. (2011), 
Table 1. Background and enhanced concentrations used in Fig. 1.

\begin{tabular}{lll}
\hline Molecule & $\begin{array}{l}\text { Background } \\
\left(\text { molec cm }^{-2}\right)\end{array}$ & $\begin{array}{l}\text { Enhanced } \\
(\text { molec cm }\end{array}$ \\
\hline $\mathrm{H}_{2} \mathrm{O}$ & $5.42 \times 10^{22}$ & $5.96 \times 10^{22}$ \\
$\mathrm{CO}_{2}$ & $8.09 \times 10^{21}$ & $8.49 \times 10^{21}$ \\
$\mathrm{O}_{3}$ & $7.35 \times 10^{18}$ & $8.08 \times 10^{21}$ \\
$\mathrm{NH}_{3}$ & $1.05 \times 10^{14}$ & $4.91 \times 10^{16}$ \\
$\mathrm{HCOOH}$ & $2.16 \times 10^{14}$ & $2.63 \times 10^{16}$ \\
\hline
\end{tabular}
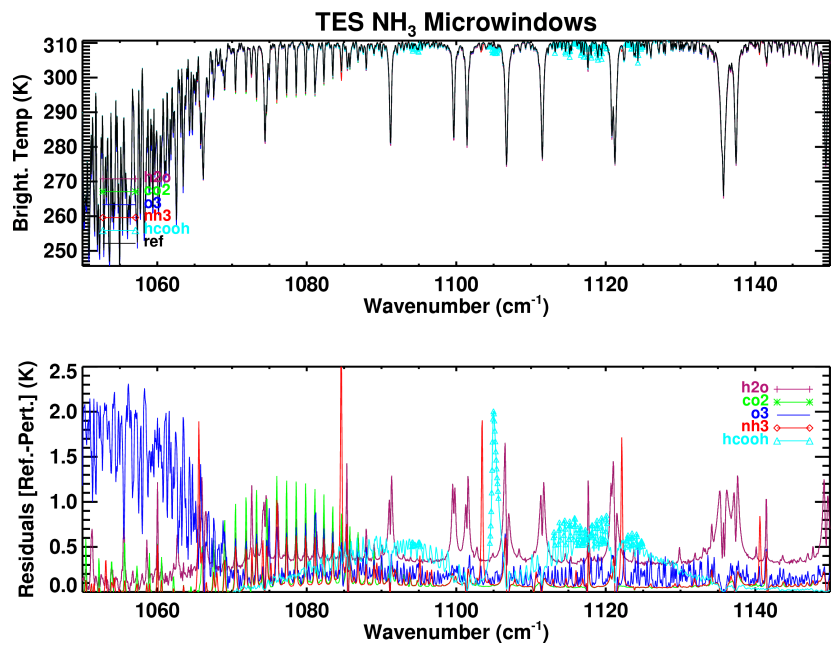

the $\mathrm{HCOOH}$ retrievals are only performed when the cloud optical depth is less than 1.0. Accurate and well-validated forward radiative transfer calculations are required for these detailed inversions. In this analysis we use OSS (Optimal Spectral Sampling)-TES, a rapid and accurate forward radiance model that employs an optimal spectral sampling technique (Moncet et al., 2008). OSS-TES is built from the LineBy-Line Radiative Transfer Model (LBLRTM) (Clough et al., 2005), which has been well validated (e.g., Shephard et al., 2009; Mlawer et al., 2012; Alvarado et al., 2013).

\subsection{TES HCOOH microwindows}

The TES HCOOH retrieval uses the $v_{6}$-vibrational band at $1105 \mathrm{~cm}^{-1}$. Figure 1 shows simulated radiance signals for relevant atmospheric species in this relatively clean spectral window region. The background and enhanced concentrations used to calculate these spectral sensitivities are given in Table 1. Note that line intensities for this region from HITRAN (High Resolution Transmission) 2008 (Rothman et al., 2009), which are based on Vander Auwera et al. (2007), are up to two times greater than the HITRAN 2004 values (Rothman et al., 2005). This large change implies that earlier $\mathrm{HCOOH}$ measurements derived using HITRAN 2004 are too large by a similar amount.

Microwindows for the TES $\mathrm{HCOOH}$ retrieval are presented in Table 2. While the $\mathrm{HCOOH}$ spectral feature in this region includes two side lobes, between 1192 and $1196 \mathrm{~cm}^{-1}$ and between 1112 and $1120 \mathrm{~cm}^{-1}$, we find that using the information in these lobes often leads to unstable retrievals when the $\mathrm{HCOOH}$ spectral signal is weak. The signal in these features tends to rise above the noise level only for large concentrations of $\mathrm{HCOOH}$.

\subsection{Building a priori profiles and constraints}

Simulated $\mathrm{HCOOH}$ mixing ratios from the GEOS-Chem CTM are shown in Fig. 2 for January and July 2004. Concentrations are elevated over the continents and in the summer hemisphere, reflecting the predominantly terrestrial and photochemical nature of the $\mathrm{HCOOH}$ sources in the model. The highest $\mathrm{HCOOH}$ levels are predicted over and downwind of regions with strong biogenic and pyrogenic emissions, such as the tropics and the southeastern United States. Only rarely

Figure 1. TES-simulated spectra and residuals. Top panel: TESsimulated spectra for background amounts of $\mathrm{H}_{2} \mathrm{O}, \mathrm{CO}_{2}, \mathrm{O}_{3}$, $\mathrm{NH}_{3}$, and $\mathrm{HCOOH}$ (black line), and for enhanced amounts of each molecule (colored lines). Note that in several cases the perturbed spectra are obscured by the reference spectrum. Bottom panel: residuals computed as the reference spectrum minus the perturbed spectra. In both panels the blue triangles show the microwindows used for the formic acid retrieval. See Table 1 for background and enhanced amounts.

Table 2. Microwindows for TES HCOOH retrievals*.

\begin{tabular}{llrrl}
\hline Index & TES filter & $\bar{v}_{1}\left(\mathrm{~cm}^{-1}\right)$ & $\bar{v}_{2}\left(\mathrm{~cm}^{-1}\right)$ & Purpose \\
\hline 1 & 1B2 & 1095.20 & 1095.32 & Surface \\
2 & 1B2 & 1104.50 & 1105.64 & HCOOH \\
3 & 1B2 & 1108.80 & 1109.06 & Surface \\
\hline
\end{tabular}

$v_{1}$ and $v_{2}$ represent the left and right edges of the microwindows.

do the simulated surface concentrations exceed $2 \mathrm{ppbv}$ (parts per billion by volume).

Alvarado et al. (2011) used GEOS-Chem output to build an initial pair of a priori profiles for retrieving $\mathrm{HCOOH}$ from TES (Fig. 3): a clean profile, defined as the average of all profiles that did not exceed $0.2 \mathrm{ppbv}$ below $500 \mathrm{hPa}$, and an enhanced profile, defined as the average of the remaining cases. The initial constraint matrices were derived from the model variability across all profiles classified as "clean" or "enhanced". These a priori values were then used for TES $\mathrm{HCOOH}$ retrievals during the NASA ARCTAS (Arctic Research of the Composition of the Troposphere from Aircraft and Satellites; Jacob et al., 2010) campaign over a boreal fire. These few retrievals successfully reduced the residuals in the $\mathrm{HCOOH}$ spectral window and returned reasonable results, but when the same a priori information was used in a set of retrievals carried out over southeastern Australia during the Black Saturday fires of 2009, the retrieval was frequently not able to find a solution. An example of this is shown in Fig. 4 

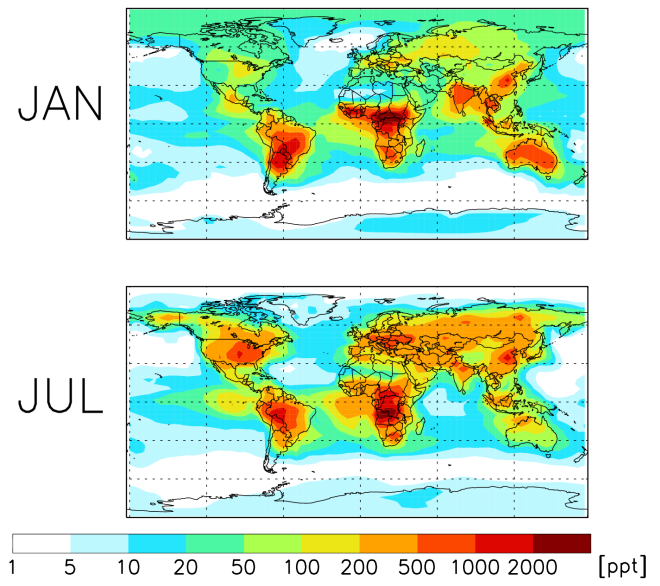

Figure 2. $\mathrm{HCOOH}$ in surface air as simulated by the GEOS-Chem model for 2004.
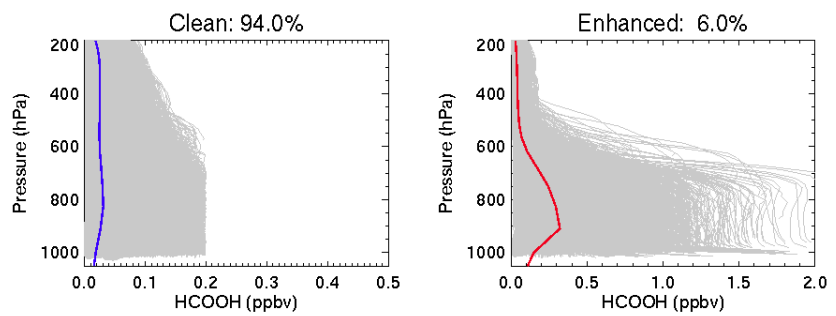

Figure 3. HCOOH profiles simulated by GEOS-Chem over the entire globe for 2004 binned by type (in grey). The mean profiles for each category are shown in color. See text for details.

(panels b and c). Further analysis of the retrieval showed that even the enhanced a priori profile led to very weak Jacobians which, when combined with a weaker $\mathrm{HCOOH}$ signal (1 K for the Australia cases versus $2 \mathrm{~K}$ for the ARCTAS case), did not allow the retrieval to reduce the residuals.

These results pointed to the need for a more enhanced a priori profile, corresponding to scenarios with much higher $\mathrm{HCOOH}$ concentrations than predicted by the CTM. This is consistent with the findings of Paulot et al. (2011), who found that atmospheric $\mathrm{HCOOH}$ tends to be underestimated by GEOS-Chem, at times by a factor of four or more. Aircraft measurements during the Intercontinental Transport Experiment-Phase B (INTEX-B) and Megacity Initiative: Local and Global Research Observations, (MILAGRO) campaigns also confirm the general tendency of GEOS-Chem to underestimate $\mathrm{HCOOH}$, as shown by the average measured and modeled profiles for these campaigns (Fig. 5). Therefore, we concluded that the current state of understanding for $\mathrm{HCOOH}$, as implemented in GEOS-Chem, does not provide an adequate representation of the distribution and variability of atmospheric $\mathrm{HCOOH}$ for deriving an appropriate a priori for the TES retrieval. We instead constructed an enhanced a priori profile based on the IASI a priori (Razavi et al., 2011) and an analysis of $\mathrm{HCOOH}$ measurements from the

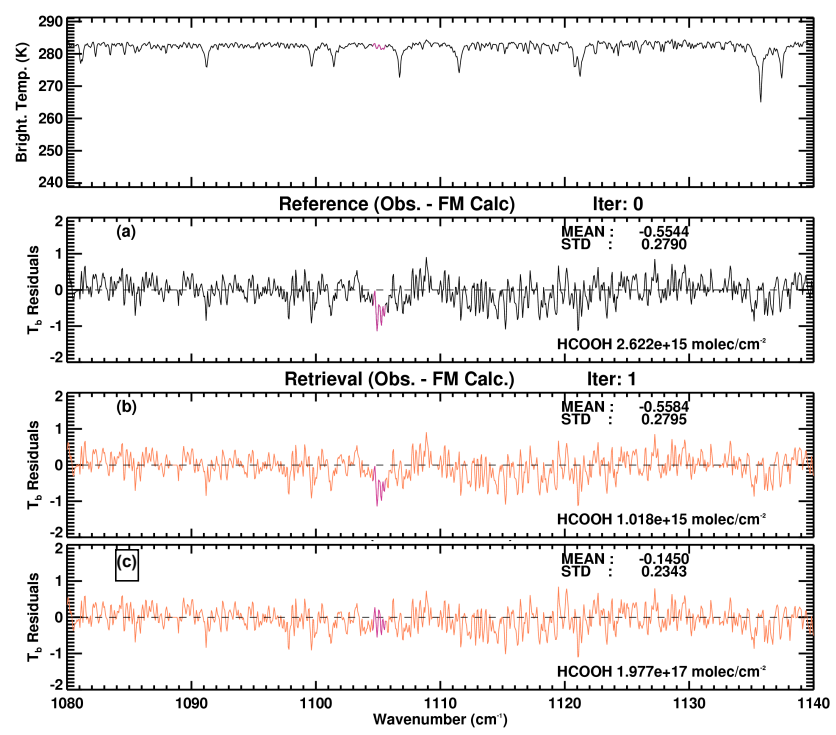

Figure 4. TES brightness temperature and retrieval residuals from an observation taken east of Australia $\left(24.33^{\circ} \mathrm{S}, 164.18^{\circ} \mathrm{W}\right)$ on 2 February 2009 during the Black Saturday fire event. TES BT (top panel); residual before retrieval (second panel); residual after retrieval with first a priori (third panel); residual after retrieval with final a priori (bottom panel).

MILAGRO campaign, and a clean a priori based on the MILAGRO data alone (Fig. 6). As we discuss in Sect. 3.3, clean profiles are in general below the TES detectability level. The diagonals of the covariance matrices used for constructing the constraint matrices were set to allow approximately $20 \%$ variability for the clean cases and $50 \%$ variability for the enhanced cases. Constraining the clean cases more tightly greatly reduces the chance of false positives, i.e., artificial detection of elevated $\mathrm{HCOOH}$ when there is little information from the observations. These constraints will be refined as needed when more global information becomes available. The refined retrieval with the enhanced prior reduces the residuals to an acceptable level, as can be seen in the bottom panel of Fig. 4.

\subsection{A priori selection}

For the TES $\mathrm{CH}_{3} \mathrm{OH}$ algorithm (Cady-Pereira et al., 2012), the a priori type is selected according to location and month from a database derived from GEOS-Chem output over the entire Earth for a year. We found that this approach was not feasible for $\mathrm{HCOOH}$, given the mismatch between the GEOS-Chem output and measured atmospheric concentrations. Instead we created an a priori selection algorithm based on the brightness temperature (BT) difference between the peak of the $\mathrm{HCOOH}$ signal and a nearby "window" region. This is similar to the approach followed for the TES $\mathrm{NH}_{3}$ retrieval (Shephard et al., 2011), and is the basis of the IASI $\mathrm{HCOOH}$ and $\mathrm{CH}_{3} \mathrm{OH}$ retrieval algorithms (Razavi et al., 

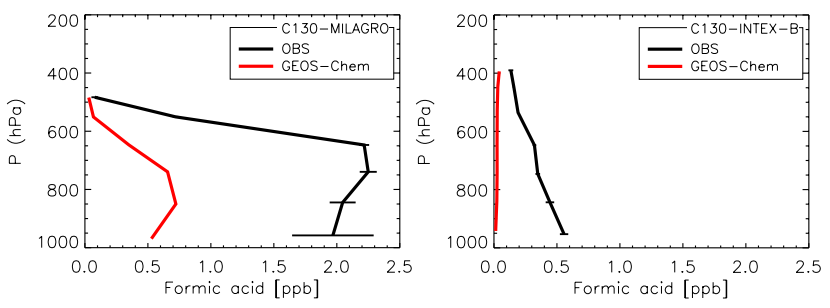

Figure 5. Mean $\mathrm{HCOOH}$ profiles from GEOS-Chem and aircraft measurements during MILAGRO (left) and INTEX-B (right).

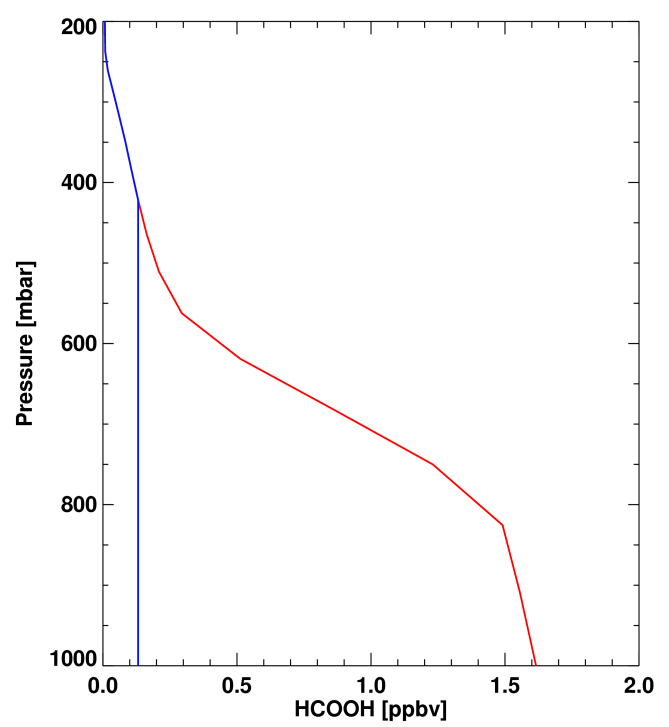

Figure 6. Clean (blue) and enhanced (red) a priori profiles.

2011). However, unlike with IASI, in this case we are only using the BT difference to select an a priori profile for use in the subsequent full optimal estimation retrieval.

Figure 7 shows a simulated TES spectrum in the region where $\mathrm{HCOOH}$ is active along with the $\mathrm{HCOOH}$ signal, defined as the difference between forward model runs with and without $\mathrm{HCOOH}$. The $\mathrm{HCOOH}$ peak and window signals are calculated over $1105.04-1105.16 \mathrm{~cm}^{-1}$ (region A) and $1108.88-1109.06 \mathrm{~cm}^{-1}$ (region B) respectively. The BT difference between the peak and window regions only provides an estimate of the true $\mathrm{HCOOH}$ signal, which can be represented by the peak outlined in red from 1104.50 to $1105.64 \mathrm{~cm}^{-1}$. The estimated and true signals are correlated, but the relationship is not exact; different atmospheric conditions (e.g., water vapor amounts, surface conditions) lead to different ratios between the two parameters. In Fig. 8 we show a scatter plot of the SNR (the true $\mathrm{HCOOH}$ signal divided by the expected noise) and the estimated signal from the BT difference, obtained from 561 different forward model runs (see details in Sect. 3.2). There is a clear linear relationship between the two, with a correlation coefficient of 0.94 . However, the degree of scatter illustrates that even in a simulation environment with no spectral noise and no
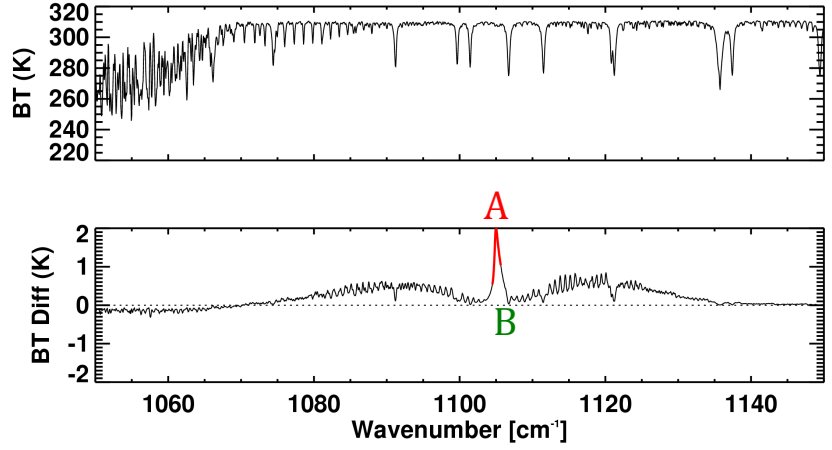

Figure 7. Simulated TES spectrum (top panel), and $\mathrm{HCOOH}$ residual (bottom panel).

retrieval errors in other species, the BT difference approach provides, at best, a first guess, which is its function in the TES HCOOH algorithm.

To select the a priori profile type to use in a particular TES $\mathrm{HCOOH}$ retrieval, the BT difference is first calculated at the spectral points listed above, and then transformed by the linear relationship shown in Fig. 8 to provide an estimate of the SNR. If the absolute value of the SNR is greater than 2 , then the enhanced a priori is used in the retrieval, otherwise the clean a priori is selected. In our discussion of the Black Saturday fire observations (Sect. 2.3), we noted that unless the a priori was significantly enhanced, the retrieval did not move towards a solution due to weak measurement sensitivity (small Jacobian values). While in many retrieval implementations the initial guess profile and the a priori are identical, this is not compulsory, and we find that in order to avoid null space issues (from weak Jacobians) in the TES $\mathrm{HCOOH}$ retrieval it is necessary to set the initial guess profile (but not the a priori profile itself) equal to the enhanced a priori in all cases.

\section{TES HCOOH product}

\subsection{TES HCOOH retrieval characteristics}

While the $\mathrm{HCOOH}$ spectral signature can be clearly seen in the residuals for the Australian Black Saturday retrieval shown in Fig. 4, $\mathrm{HCOOH}$ is only weakly absorbing, and thus the retrieval can only provide a limited amount of information. The averaging kernel in the sample retrieval in Fig. 9 has 0.92 degrees of freedom for signal (DOFS) and is most sensitive between 800 and $700 \mathrm{hPa}$. This averaging kernel shape is typical of the TES $\mathrm{HCOOH}$ retrievals, where the peak in vertical sensitivity ranges from 900 to $600 \mathrm{hPa}$ depending on the atmospheric state (e.g., thermal contrast, concentration of $\mathrm{HCOOH}$, and temperature profile). However, the DOFS are usually lower than in this example: for 7700 successful TES retrievals performed over land during July 2009, $54 \%$ had 


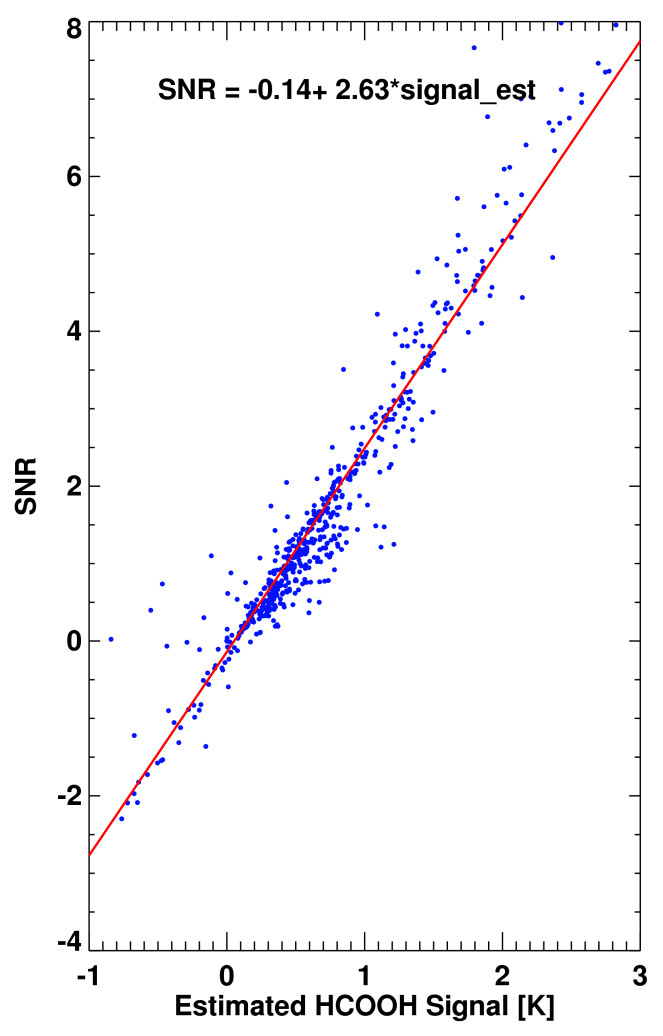

Figure 8. HCOOH SNR vs. estimated $\mathrm{HCOOH}$ signal (see text for definitions) with linear fit parameters.

DOFS $>0.1$, and of those, $54 \%$ had DOFS $>0.5$ and $24 \%$ had DOFS $>0.8$.

Since there are often one or fewer pieces of information in an individual measurement, the shape of the retrieved profile is strongly determined by the a priori profile. Retrieving column (or partial column) scale factors rather than vertically resolved full profiles is a common strategy adopted where there is limited vertical information provided by the measurement. However, this implicitly assumes a profile shape and that the measurement is equally sensitive over all of the retrieved column. Performing the $\mathrm{HCOOH}$ retrieval on a number of vertical profile levels has the advantage of capturing the region of maximum vertical sensitivity for each case, which varies from profile to profile depending on the atmospheric state.

The fact that the retrieval is carried out on multiple vertical levels does not mean that the retrieved profile shape will adjust fully to the true profile in all cases. There is not sufficient information in the TES signal for this to occur. In particular, the shape of the a priori profile employed in the TES retrieval is meant to reflect average conditions globally, and there are likely to be situations where $\mathrm{HCOOH}$ is enhanced aloft and the assumed shape thus does not accurately capture the true vertical distribution. For example, the retrieved profile over the intense Australian Black Saturday fire shown in Fig. 9 peaks around 825 mbar, whereas the true peak in

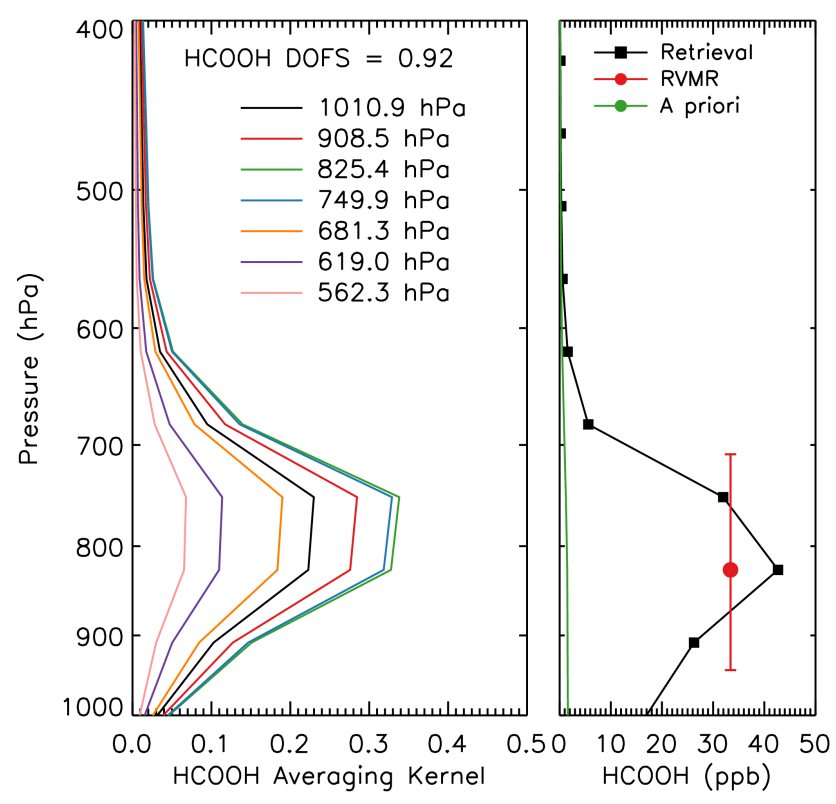

Figure 9. Averaging kernel (left) and retrieved $\mathrm{HCOOH}$ profile (right) from the TES spectrum shown in Fig. 4. The red circle shows the HCOOH RVMR and the red lines show the vertical extent over which the RVMR applies. The green line is the enhanced a priori profile.

this instance may be much higher in the atmosphere. This in an unavoidable issue when developing a general algorithm for all conditions; it is possible to create an a priori profile and a constraint matrix for specific situations, such as strong biomass burning plumes, which would return more accurate profiles, but we have not attempted this procedure here.

Given the low amount on information on the profile shape we use the Representative Volume Mixing Ratio (RVMR) (Payne et al., 2009; Shephard et al., 2011) method to map the retrieved profile VMRs to a subset of values that are more representative of the information content provided by TES; in the case of $\mathrm{HCOOH}$ this is typically one value. In other words, we aggregate the information provided by the satellite into a single metric that is minimally affected by the retrieval a priori:

$\mathrm{RVMR}=\sum_{i} \boldsymbol{w}_{i} \boldsymbol{x}_{i}$

where for each level $i, \boldsymbol{w}$ is the weighting function (in $\log$ space) derived from the TES sensitivity as represented by the averaging kernel, and $\boldsymbol{x}$ is the log of the retrieved mixing ratio. An example $\mathrm{HCOOH}$ RVMR is shown for the Black Saturday fires in Fig. 9 with the representative vertical range of the RVMR also indicated.

\subsection{Results from simulated retrievals}

We carried out a series of simulated retrievals to test the performance of the TES $\mathrm{HCOOH}$ measurement in a situation 

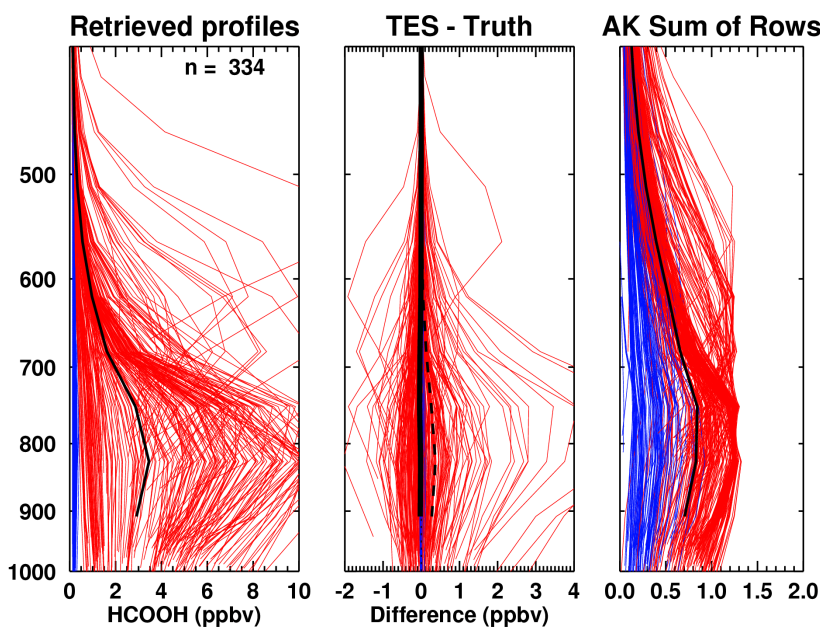

Figure 10. Simulated $\mathrm{HCOOH}$ retrievals over North America in July 2008. Colored curves indicate the a priori selection (blue: clean, red: enhanced). Left panel: retrieved profiles, with the mean retrieved profile in black. Middle panel: retrieved minus true profiles. The solid line shows the mean bias, while the dashed line shows the standard deviation of the bias. Right panel: sum of the averaging kernel rows (SRAK) for each profile, with the mean in black. Means and standard deviations are not calculated for the surface level, since the height of this level ranges from above 1000 to less than $800 \mathrm{hPa}$.

where the "true" $\mathrm{HCOOH}$ profile is known. Simulated TES spectra were calculated from 561 TES Level 2 profiles with prescribed ("truth") $\mathrm{HCOOH}$ profiles. These simulated $\mathrm{HCOOH}$ profiles were generated by applying a scale factor to either the clean or the enhanced a priori profile; the scale factor was calculated as the product of a value ranging from 10 at the surface to 1 above $300 \mathrm{mbar}$, and a random variable ranging between 0.5 and 1.0. The simulated radiances were computed for each profile by adding random noise that is typical of the actual TES instrument noise in this spectral region $(0.2-0.3 \mathrm{~K})$. These simulated radiances were then provided as inputs to the retrieval algorithm. The a priori profile was selected according to the algorithm described in Sect. 2.4, and the initial guess was set to the enhanced a priori.

From the 561 spectra, we obtained 334 retrieved profiles with DOFS greater than 0.1 , and the TES observational operator (defined in the Appendix) was then applied to the prescribed "true" $\mathrm{HCOOH}$ profiles. Retrievals with DOFS $<0.1$ were excluded from the following analysis, since after applying the TES operator the "true" and retrieved profiles in those cases would both be very similar to the a priori profile, which would bias the statistics.

Under these ideal simulated conditions where the truth is known, profile comparisons of the retrieved versus true profiles in Fig. 10 show that the retrievals have a very small mean bias of $-0.02 \mathrm{ppbv}$, with a standard deviation (SD) of $\pm 0.37 \mathrm{ppbv}$ at $825 \mathrm{hPa}$. More insight can be gained by binning the retrieval bias and variance according to the a priori
Table 3. Simulated retrieval results at $825 \mathrm{hPa}$.

\begin{tabular}{lrll}
\hline A priori & Mean (ppbv) & Bias (ppbv) & SD $(\sigma)$ \\
\hline Clean & 0.20 & $-0.005(2.5 \%)$ & $\pm 0.02(10 \%)$ \\
Enhanced & 5.02 & $-0.06(1.2 \%)$ & $\pm 0.61(12 \%)$ \\
\hline
\end{tabular}

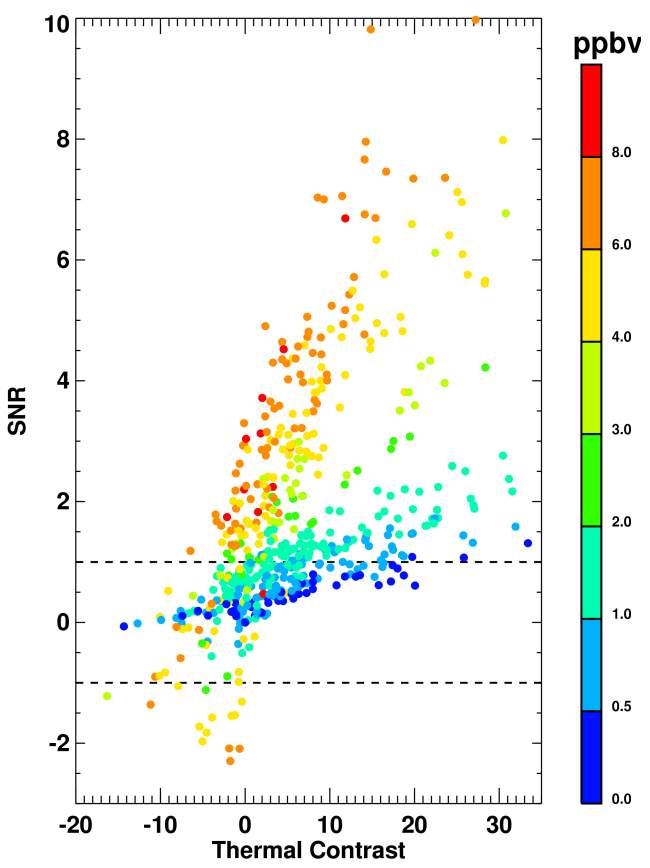

Figure 11. Signal-to-noise ratio (SNR) vs. thermal contrast, color coded by the maximum concentration of each profile.

type, as show in Table 3. Our simulated data set contains 100 cases with a clean a priori and 234 with an enhanced a priori. Note that the set of profiles classified as clean have retrievals that are significantly influenced by the a priori, and thus are expected to have a low bias; however, the retrievals over the enhanced profiles also have a very low bias $(-0.06 \mathrm{ppbv})$ overall. These results demonstrate that the retrieval strategy performs well under ideal conditions where everything in the atmospheric state is known perfectly except $\mathrm{HCOOH}$.

Figure 10 shows that the TES retrieval tends to adjust the amount of $\mathrm{HCOOH}$ in the vertical region where TES is most sensitive, between 700 and $900 \mathrm{hPa}$. Although this is an expected result for a satellite-based infrared nadir retrieval, the overall retrieved profile shape can become somewhat distorted compared with the a priori or initial guess as the measurement is insensitive to certain parts of the vertical profile (e.g., at the surface or above $500 \mathrm{mb}$ ). In general, this type of behavior will occur when the sensitivity of the infrared signal varies throughout the vertical column (as is the case for $\mathrm{HCOOH}$ ). Use of the RVMR provides a key advantage in this regard for comparing TES data with in situ measurements or with model output, as it allows the comparison to be performed where the satellite observation actually provides information. 


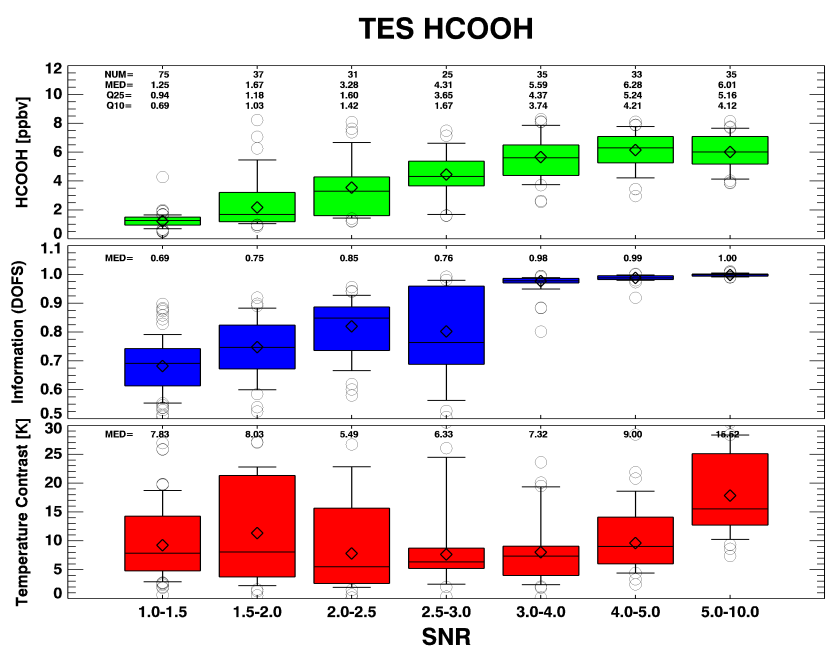

Figure 12. Thermal contrast, DOFS and maximum $\mathrm{HCOOH}$ value vs. SNR for simulated retrievals.

\subsection{TES HCOOH detection threshold}

The minimum concentration threshold for detecting $\mathrm{HCOOH}$ from TES can be defined as the value where the $\mathrm{SNR} \equiv 1$; below that point the retrieved value is principally determined by the a priori. In Fig. 11 we show the SNR, defined in Sect. 2.4, as a function of the thermal contrast (the difference between the surface temperature and the air temperature at the first retrieval level) for the set of simulated radiances discussed in the previous section. The points have been color-coded based on the maximum concentration of each "true" profile. The environmental conditions (e.g., surface properties, and atmospheric temperature profile) impact the infrared signal for a given $\mathrm{HCOOH}$ abundance. We see that profiles with a maximum $\mathrm{HCOOH}$ concentration below roughly $0.5 \mathrm{ppbv}$ are in general not detectable by TES, and thermal contrast plays a significant role in the strength of the $\mathrm{HCOOH}$ signal: even cases with high amounts (>4.0 ppbv) may have a very low SNR with low thermal contrast, (less than $5 \mathrm{~K}$ ) while fairly low-HCOOH cases $(<1 \mathrm{ppbv})$ may have a SNR over 1 if the thermal contrast is high enough ( $>15 \mathrm{~K}$ ). If we examine the statistics of the cases with SNR greater than 1, binned by SNR, (Fig. 12), we can refine the detection threshold. If we look at the results in the bin with lowest SNR values, and set as a detection threshold the maximum $\mathrm{HCOOH}$ in the 7590th percentile range, then we can state that the minimum detection threshold lies between 0.69 and $0.94 \mathrm{ppbv}$, though, as shown in Fig. 11, this requires significant thermal contrast.

When using remote sensing data, one frequently needs to assess how much information for a given retrieval is being provided by the measurement, as opposed to the a priori assumption. In the case of the TES HCOOH measurements, the end user has no information on the SNR values; however, the retrieval does provide the DOFS, which, as shown in the middle panel of Fig. 12, are fairly well correlated with

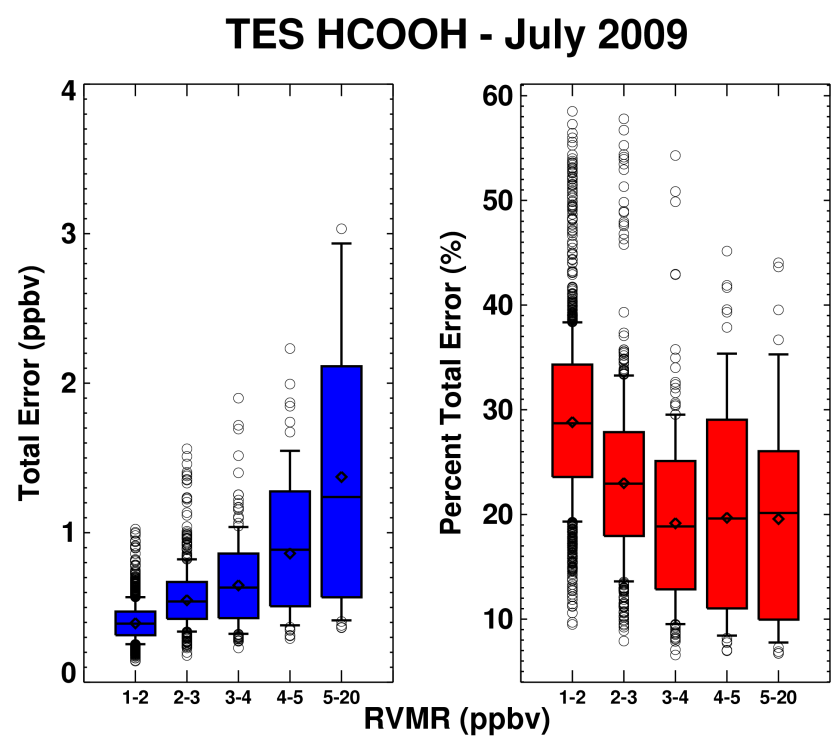

Figure 13. HCOOH RVMR-estimated errors for a TES Global Survey from July 2009, binned by RVMR value: absolute error (left panel), percent error (right panel).

the signal strength, though they tend asymptotically to 1.0 for high SNR. When the HCOOH signal is less than the noise level $(\mathrm{SNR}<1)$ the DOFS are generally less than 0.5 . This implies that the retrieved profile will be very similar to the prior or, equivalently, that the retrieval has added little to the estimate of the true state. There are a number of circumstances that can lead to retrieved $\mathrm{HCOOH}$ amounts with low DOFS, including clean conditions with low concentrations of $\mathrm{HCOOH}$, cold scenes with limited infrared radiance, thicker cloud, and cases with little thermal contrast between the surface and the atmospheric layers containing $\mathrm{HCOOH}$, as shown in Fig. 11. Thus, the DOFS can be used as a rough criteria for accepting or rejecting retrievals in an analysis.

\subsection{TES HCOOH error estimates}

Error estimates derive directly from optimal estimation retrievals (Rodgers 2000; Worden et al., 2004); see Eq. (A3) in the Appendix. These retrieval errors can then be mapped into the RVMR space via the same weighting matrix $(W)$ used to calculate the RVMR itself (Cady-Pereira et al., 2012):

$\mathbf{E}=\mathbf{W H}^{-1} \mathbf{W}^{T}$,

where $\mathbf{E}$ is the error in the RVMR, and $\mathbf{H}$ is the Hessian, computed as

$\mathbf{H}=\mathbf{S}_{\mathrm{a}}^{-1}+\mathbf{K}^{T} \mathbf{S}_{\mathrm{n}}^{-1} \mathbf{K}$

(refer to the Appendix for definitions of $\mathbf{S}_{\mathrm{a}}, \mathbf{K}$, and $\mathbf{S}_{\mathrm{n}}$ ).

Figure 13 shows estimated errors in the $\mathrm{HCOOH}$ RVMR for a TES Global Survey from July 2009. The absolute error lies in general between 0.5 and $1.0 \mathrm{ppbv}$, and increases with 

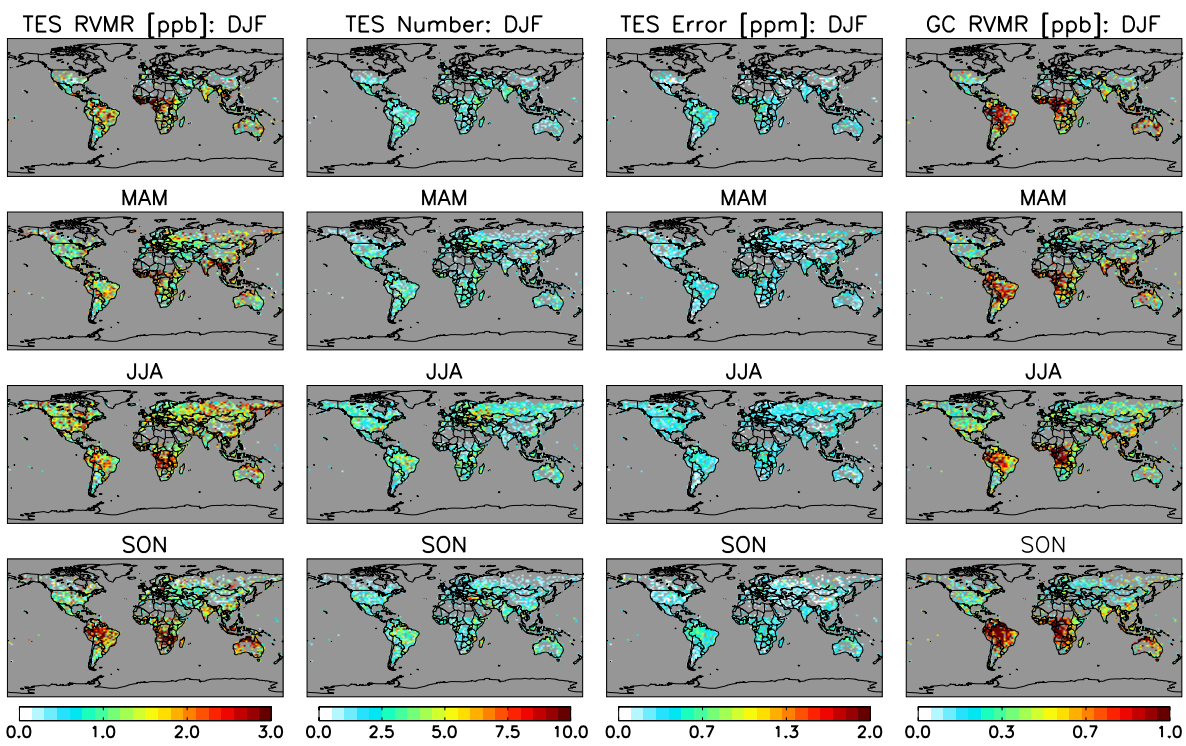

Figure 14. 2009 HCOOH: TES RVMR (column 1), number of TES observations (column 2), TES estimated error (column 3 ) and GEOSChem with TES operator applied (column 4).

increasing $\mathrm{HCOOH}$; while there are some large outliers in the relative error, especially when $\mathrm{HCOOH}$ is low, the estimated relative errors are mostly in the $10-35 \%$ range.

For the error analysis performed here we have not explicitly taken into consideration any systematic components (i.e., the last term in Appendix Eq. A3). One potential source of systematic error in the retrieval is uncertainty in the spectroscopic parameters; for example, line intensity errors would yield directly proportional errors in the retrieved $\mathrm{HCOOH}$ concentrations. $\mathrm{HCOOH}$ spectroscopic parameters used in these retrievals are from the HITRAN 2008 database (Rothman et al., 2009), with estimated uncertainties in the line intensities of $\sim 7 \%$ (Vander Auwera et al., 2007). Since this error is small relative to the overall estimated error for the TES HCOOH measurement it is ignored for this initial analysis, but could be important for future retrieval improvements. Another potential source of systematic error is the propagation of errors from other retrieved parameters (i.e., temperature, water vapor retrievals, surface temperature and emissivity) onto the $\mathrm{HCOOH}$ retrieval. We have not taken into account these systematic or cross-state errors in this initial analysis. Our assumption is that these errors are small relative to the estimated random errors, as the retrieval microwindow is narrow and the first step of the retrieval (i.e., for surface temperature and emissivity) will have reduced the background radiance residuals to (or close to) the noise level. Conclusive characterization of the full uncertainty (i.e., both systematic and random components) in the TES HCOOH measurements requires comparisons with independent data; such comparisons will be presented in a subsequent paper.

\section{Results from TES global surveys}

Figure 14 shows the global and seasonal distribution of atmospheric $\mathrm{HCOOH}$ as measured by TES (2009 Global Surveys) and as simulated for the same year by GEOS-Chem. Due to the low SNR over the oceans (from the expected low $\mathrm{HCOOH}$ concentrations and reduced thermal contrast), we include here only retrievals over land. There is also a paucity of successful $\mathrm{HCOOH}$ observations over desert regions such as North Africa and the Arabian Peninsula, due to retrieval challenges arising from the strong silicate spectral feature in surface emissivity for these areas.

The GEOS-Chem $\mathrm{HCOOH}$ simulation is as described by Paulot et al. (2011), with recent updates (Chaliyakunnel et al., 2014). In particular, biogenic VOC emissions are computed in the model based on MEGANv2.1 (Model of Emissions of Gases and Aerosols from Nature; Guenther et al., 2012), using plant functional type distributions from the Community Land Model version 4.0 (Lawrence et al., 2011). Biomass burning emissions are derived from the GFEDv3 (Global Fire Emissions Database) database (van der Werf et al., 2010). The GEOS-Chem chemical mechanism has been updated here to include explicit treatment of Criegee intermediates as well as the recently proposed production of vinyl alcohol (and subsequently $\mathrm{HCOOH}$; Archibald et al., 2007; So et al., 2014) from the keto-enol tautomerization of acetaldehyde (Andrews et al., 2012; Clubb et al., 2012). The latter accounts for some $20 \%$ of the global $\mathrm{HCOOH}$ burden in the model, which likely represents an upper limit as our implementation here does not account for losses of vinyl alcohol other than oxidation by OH (So et al., 2014; Karten, 2014; da Silva, 2010). The resulting $\mathrm{HCOOH}$ source totals 


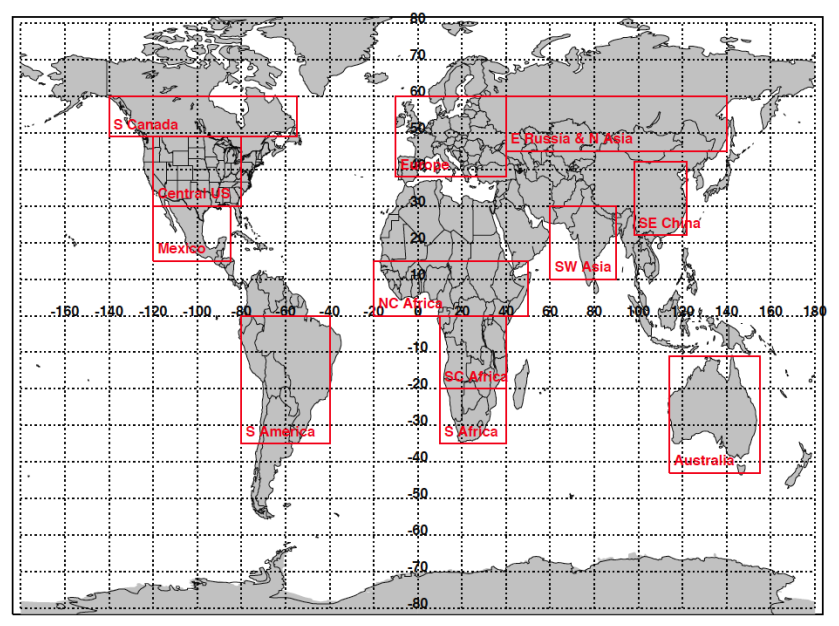

Figure 15. Regions used for aggregating data for Figs. 16 and 17.

$55 \mathrm{Tg}$ globally in 2009 , including $47 \mathrm{Tg}$ from photochemical production, $4.2 \mathrm{Tg}$ from direct biogenic emissions (including soils), $1.5 \mathrm{Tg}$ from direct fire emissions, and $2.6 \mathrm{Tg}$ from anthropogenic and agricultural sources.

The global, average atmospheric lifetime of $\mathrm{HCOOH}$ in the model is 3.3 days, with sinks due to dry deposition (accounting for $39 \%$ of the total sink in 2009) computed based on a standard resistance-in-series scheme (Wesely, 1989), wet deposition as described by Amos et al. (2012) (38\%), and photochemical oxidation by $\mathrm{OH}(23 \%)$.

For each successful TES HCOOH retrieval over land with DOFS $>0.1$ we sample GEOS-Chem at the time and location of the measurement, and apply the TES observational operator to the model profile. The first step ensures that model grid boxes not sampled by TES are excluded from the analysis, while the last step provides a self-consistent comparison that accounts for the vertical sensitivity of the satellite measurement. We then compute RVMR values for both TES and GEOS-Chem as described in Sect. 3.1; these are then averaged seasonally and onto the $2^{\circ} \times 2.5^{\circ}$ GEOS-Chem model grid. The number of valid retrievals and the mean error in each box are also calculated.

We see in Fig. 14 that the broad spatial distribution of $\mathrm{HCOOH}$ simulated by GEOS-Chem has some similarities to that observed by TES. For example, in both cases there are elevated $\mathrm{HCOOH}$ concentrations in the tropics and in the Northern Hemisphere during summer, and biomass burning seasons are obvious in Africa and South America. However, the model RVMRs are persistently low compared to TES, typically by a factor of two or more. Since the number of TES observations in any given model grid box is usually low (Fig. 14, second column), and the errors are a significant fraction of the retrieved value (Fig. 14, third column), we have aggregated the TES and GEOS-Chem results by regions (Fig. 15), in order to obtain more meaningful statistics (Figs. 16 and 17, respectively).
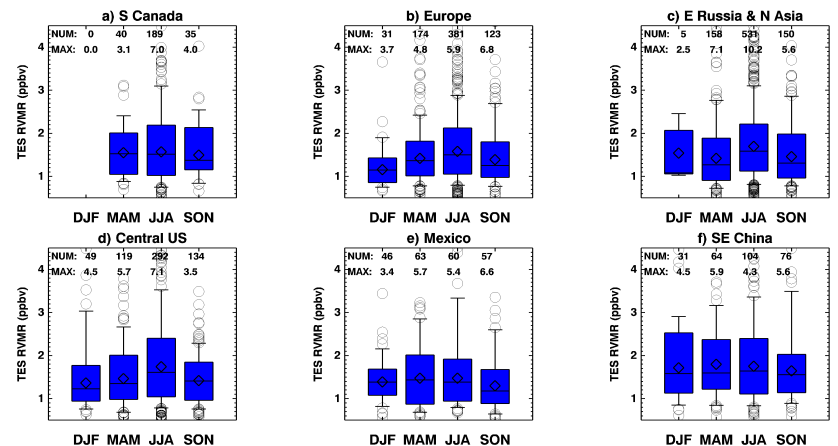

DJF MAM JJA SON
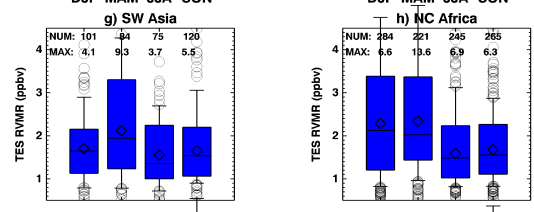

DJF MAM JJA SON

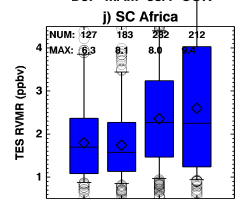

DJF MAM JJA SON
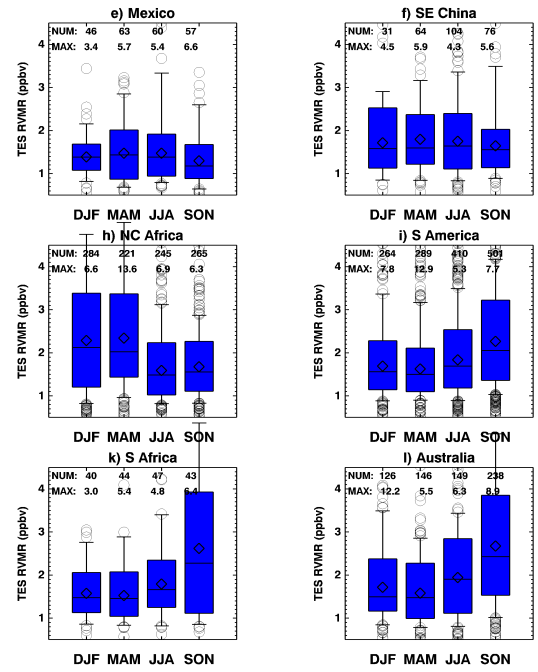

DJF MAM JJA SON

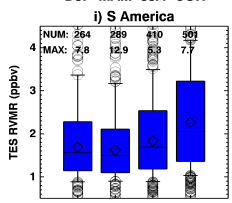

DJF MAM JJA SON

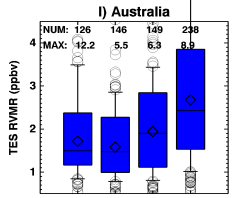

DJF MAM JJA SON

Figure 16. Statistics of the TES HCOOH RVMR values in Fig. 14 for each region in Fig. 15. Boxes indicate the 25th and 75th percentiles, the line and diamond correspond to the median and the mean, the whiskers indicate the 10th and 90th percentiles, and the outliers are represented by the circles.
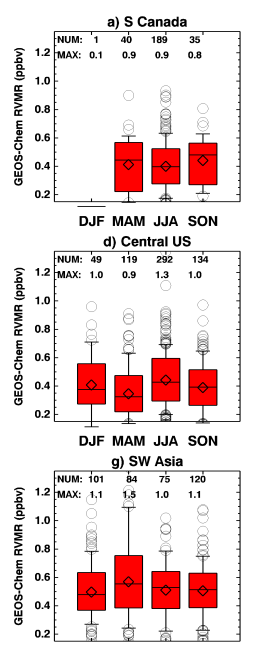

DJF MAM JJA SON

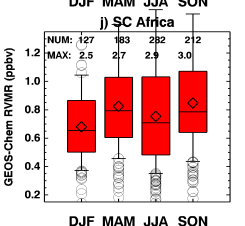

DJF MAM JJA SON

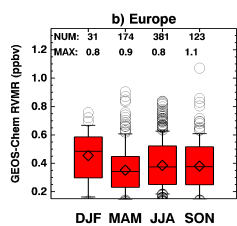

DJF MAM JJA SON
e) Mexico

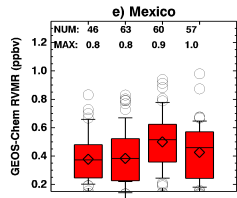

DJF MAM JJA SON

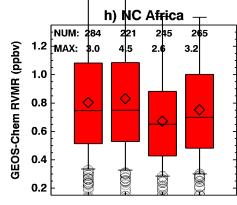

DJF MAM JJA SON

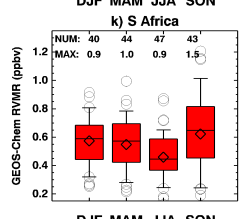

DJF MAM JJA SON

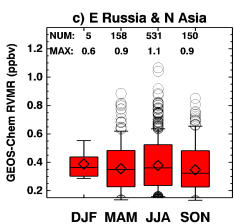

DJF MAM JJA SON

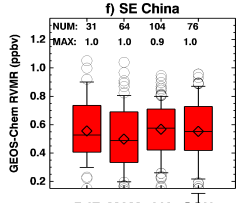

D.JF MAM JJA SON

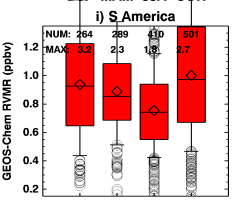

DJF MAM JJA SON

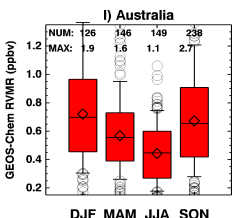

Figure 17. As in Fig. 16, but for the GEOS-Chem RVMR values in Fig. 14 and different vertical scale. 

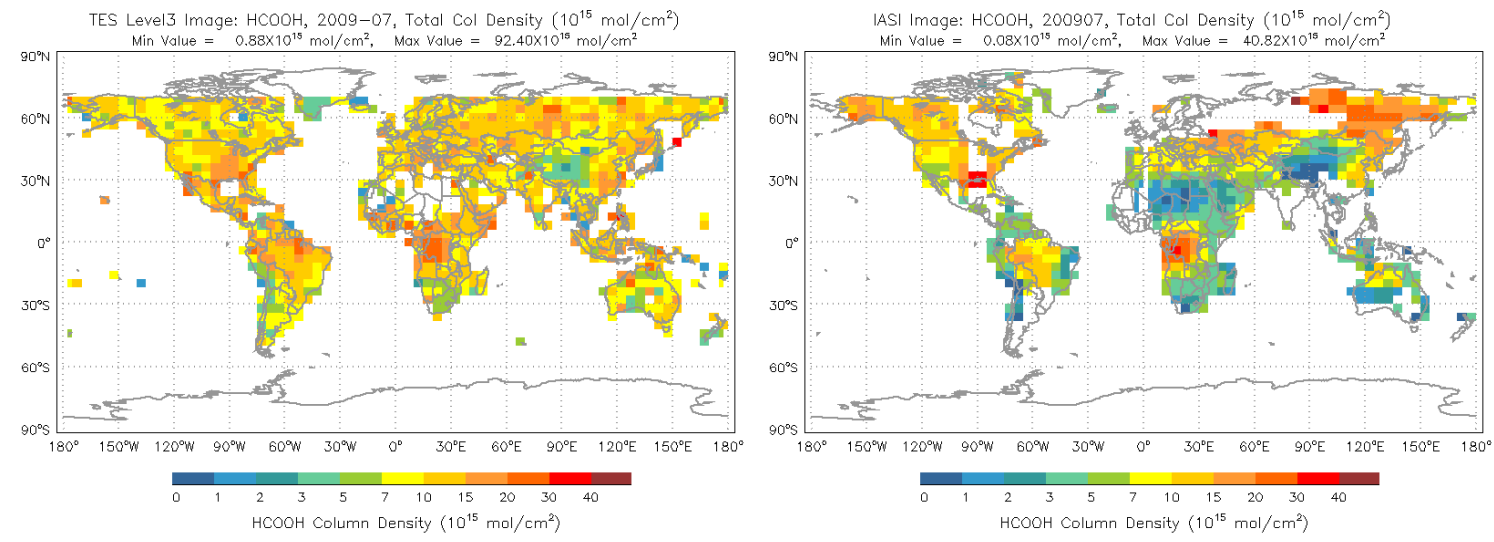

Figure 18. HCOOH total columns for July 2009 for TES (left) and IASI (right).

The aggregated results confirm the similarity in the seasonal cycle in most regions, most notably over Australia, South America, Mexico, northern Central Africa and southern Africa, but also highlight the much weaker seasonal amplitude. The most pronounced model-measurement discrepancies seen in Fig. 14 occur in summertime and seasonally over biomass burning regions (e.g., Amazonia, Africa, northern Australia). The model concentrations are also somewhat elevated during those times, but nonetheless exhibit a dramatic low bias compared to TES. This suggests a significant missing source of $\mathrm{HCOOH}$ from biogenic as well as pyrogenic sources, either through direct emission or secondary production from co-emitted precursors (Stavrakou et al., 2012; Paulot et al., 2011). The TES data thus corroborate other recent studies based on aircraft, surface FTS, and satellite measurements that have pointed to large-scale missing sources of atmospheric HCOOH (Stavrakou et al., 2012; Paulot et al., 2011). That these $\mathrm{HCOOH}$ measurements are obtained from very different sensors and a variety of methods strengthens the argument for these missing sources. As an illustration of the general agreement between TES and IASI $\mathrm{HCOOH}$ we have calculated the mean TES total columns on the $4 \times 5$ degree grid used by the IASI team for July 2009 (Fig. 18). Even though the total column obtained for each sensor is influenced by the a priori profile adopted for that sensor, regions with enhanced $\mathrm{HCOOH}$ present values in the same range: central Brazil (15-20 molec $\left.\mathrm{cm}^{-2}\right)$, eastern subSaharan Africa $\left(30-40\right.$ molec cm$\left.^{-2}\right)$, the eastern US (20$40 \mathrm{molec} \mathrm{cm}^{-2}$ ) and eastern Siberia (10-30 molec $\mathrm{cm}^{-2}$ ), though some of the IASI values are higher in this region. We are working on validating the TES $\mathrm{HCOOH}$ product (Chaliyakunnel et al., 2014) and will carry out a more extensive and quantitative comparison between TES and IASI $\mathrm{HCOOH}$. We will also apply the TES data to investigate the missing $\mathrm{HCOOH}$ sources.

\section{Conclusions}

Advances in infrared satellite observations are providing new global information on atmospheric species with relatively weak spectral signals, and have potential to yield valuable insights on processes driving tropospheric chemistry and air quality. In this paper, we presented the TES $\mathrm{HCOOH}$ retrieval, including the overall strategy, algorithm specifics, and error characterization.

Simulated retrievals show that because of its relatively weak spectral signature, measurements of $\mathrm{HCOOH}$ from TES in general have at most 1.0 DOFS, and usually less. The TES HCOOH retrieval is most sensitive in the mid-tolower troposphere $(850-600 \mathrm{hPa})$, with a vertical resolution of $\sim 2 \mathrm{~km}$. The minimum detection limit for TES HCOOH is a peak profile value of $\sim 0.7 \mathrm{ppbv}$ under conditions with strong thermal contrast $(\sim 10 \mathrm{~K})$, with the detection limit increasing as thermal contrast decreases. The ensemble of simulated $\mathrm{HCOOH}$ retrievals also show that under ideal conditions, and in the absence of systematic errors in the spectroscopic parameters or in other retrieved quantities, the TES $\mathrm{HCOOH}$ retrievals are unbiased with a standard deviation of \pm 0.3 ppbv. This indicates that the initial $\mathrm{HCOOH}$ retrieval strategy for TES performs well. Applying the retrieval algorithm to real TES global observations from 2009 and comparing them with the GEOS-Chem CTM, we find that TES is in general spatially and temporally coherent with the model results in terms of the global distribution of tropospheric $\mathrm{HCOOH}$. However, TES HCOOH is universally higher than predicted by GEOS-Chem, and this is in agreement with recent work pointing to a large missing source of atmospheric $\mathrm{HCOOH}$. The model bias is especially pronounced during summer and over biomass burning regions. In situ and laboratory measurements as well as top-down information from instruments such as TES are needed to elucidate these sources and quantify their global significance. 
Appendix A: Brief summary of the optimal estimation approach

The TES retrieval strategy uses an optimal estimation approach that minimizes the difference between the spectral radiances measured by TES and a nonlinear radiative transfer forward model. Since the retrieval is nonlinear, an a priori constraint is used for estimating the true state (Bowman et al., 2006). If the estimated (retrieved) state is close to the actual state, then the estimated state can be expressed in terms of the actual state through the linear retrieval (Rodgers, 2000):

$\hat{x}=x_{\mathrm{a}}+\mathbf{A}\left(\boldsymbol{x}-\boldsymbol{x}_{\mathrm{a}}\right)+\mathbf{G} \boldsymbol{n}+\mathbf{G K}_{b}\left(\boldsymbol{b}-\boldsymbol{b}_{\mathrm{a}}\right)$,

where $\hat{x}, \boldsymbol{x}_{\mathrm{a}}$, and $\boldsymbol{x}$ are the retrieved, a priori, and the "true" state vectors respectively. The gain matrix, $\mathbf{G}$, maps from spectral radiance space into retrieval parameter space, and the vector $\boldsymbol{n}$ represents the noise on the measured spectral radiances. The vector $\boldsymbol{b}$ represents the true state for other parameters that are not measured in the $\mathrm{HCOOH}$ retrieval itself, but that may nonetheless impact the $\mathrm{HCOOH}$ retrieval results (e.g., concentrations of interfering gases, calibration, etc.). The vector $\boldsymbol{b}_{\mathrm{a}}$ contains the corresponding a priori values, and $\mathbf{K}=\partial \mathbf{L} / \partial \boldsymbol{b}$ is a Jacobian describing the dependence of the forward model radiances $\mathbf{L}$ on the parameters in vector b.

The averaging kernel, $\mathbf{A}$, describes the sensitivity of the retrieval to the true state:

$\mathbf{A}=\frac{\partial \dot{\hat{x}}}{\partial x}=\left(\mathbf{K}^{T} \mathbf{S}_{\mathrm{n}}^{-1} \mathbf{K}+\mathbf{S}_{\mathrm{a}}^{-1}\right)^{-1} \mathbf{K}^{T} \mathbf{S}_{\mathrm{n}}^{-1} \mathbf{K}=\mathbf{G K}$,

where $\mathbf{S}_{\mathrm{n}}$ is the instrument noise covariance matrix, and $\mathbf{S}_{\mathrm{a}}$ is the a priori constraint matrix for the retrieval. The Jacobian, $\mathbf{K}$, is the sensitivity of the forward model radiances to the state vector of the parameters being retrieved (in this case, $\mathrm{HCOOH}$ mixing ratios), $\mathbf{K}=\partial L / \partial \boldsymbol{x}$.
The rows of $\mathbf{A}$ are functions (often Gaussian in shape for nadir infrared observations) with a finite width corresponding to the vertical resolution of the retrieved parameter. The sum of each row of $\mathbf{A}$ provides a measure of the fraction of retrieval information that comes from the measurement rather than the a priori (Rodgers, 2000) at the corresponding altitude, provided that the retrieval is close to linear. The trace of the averaging kernel matrix gives the number of DOFS from the retrieval.

The total error covariance matrix $\mathbf{S}_{x}$ for a given retrieved parameter $\boldsymbol{x}$ on the retrieved levels $i$ is given by

$$
\begin{aligned}
\mathbf{S}_{x} & =\left(\mathbf{A}_{x x}-\mathbf{I}\right) \mathbf{S}_{\mathrm{a}}\left(\mathbf{A}_{x x}-\mathbf{I}\right)^{T}+\mathbf{G} \mathbf{S}_{\mathrm{n}} \mathbf{G}^{T} \\
& \left.+\mathbf{G K}_{b} \mathbf{S}_{b}(\mathbf{G K})_{b}\right)^{T}
\end{aligned}
$$

where $\mathbf{S}_{b}$ is the expected covariance of the nonretrieved parameters. The total error for a retrieved profile is expressed as the sum of (i) the smoothing errors (first term on the righthand side), i.e., the uncertainty due to unresolved fine structure in the profile; (ii) the measurement errors (second term) originating from random noise in the spectrum; and (iii) the systematic errors (last term) due to uncertainties in the nonretrieved forward model parameters, some of which are constant and some of which change from retrieval to retrieval (Worden et al., 2004).

When comparing modeled profiles to retrieved profiles it is necessary to calculate the profile the instrument would retrieve if it were measuring the atmosphere as represented in the model, rather than the true atmosphere. This is done by applying the TES operator, i.e., calculating the first two terms in Eq. (A1) with $\boldsymbol{x}$ as the model profile. 
Acknowledgements. We thank Tom Connor, Alan Lipton, JeanLuc Moncet, and Gennady Uymin of AER for building an OSS version for TES. We also thank Paul Wennberg and the MILAGRO and INTEX-B teams for providing the data from these campaigns and the IASI team at the Universite Libre de Bruxelles for providing the IASI HCOOH data. Research at JPL was supported under contract to the National Aeronautics and Space Administration (NASA). Research at AER was supported under contract to NASA and the University of Minnesota. Work at UMN was supported by NSF through the Atmospheric Chemistry Program (grant no. AGS-1148951), by NASA through the Atmospheric Chemistry Modeling and Analysis Program (grant no. NNX10AG65G), and by the University of Minnesota Supercomputing Institute. The TES $\mathrm{HCOOH}$ product is available at http://tes.jpl.nasa.gov/data/.

Edited by: E. C. Apel

\section{References}

Alvarado, M. J., Cady-Pereira, K. E., Xiao, Y., Millet, D. B., and Payne, V. H.: Emission Ratios for Ammonia and Formic acid and Observations of Peroxy Acetyl Nitrate (PAN) and Ethylene in Biomass Burning Smoke as Seen by the Tropospheric Emission Spectrometer (TES), Atmosphere, ISSN 2073-4433, doi:10.3390/atmos2040633, 2011.

Alvarado, M. J., Payne, V. H., Mlawer, E. J., Uymin, G., Shephard, M. W., Cady-Pereira, K. E., Delamere, J. S., and Moncet, J.L.: Performance of the Line-By-Line Radiative Transfer Model (LBLRTM) for temperature, water vapor, and trace gas retrievals: recent updates evaluated with IASI case studies, Atmos. Chem. Phys., 13, 6687-6711, doi:10.5194/acp-13-6687-2013, 2013.

Amos, H. M., Jacob, D. J., Holmes, C. D., Fisher, J. A., Wang, Q., Yantosca, R. M., Corbitt, E. S., Galarneau, E., Rutter, A. P., Gustin, M. S., Steffen, A., Schauer, J. J., Graydon, J. A., Louis, V. L. St., Talbot, R. W., Edgerton, E. S., Zhang, Y., and Sunderland, E. M.: Gas-particle partitioning of atmospheric $\mathrm{Hg}(\mathrm{II})$ and its effect on global mercury deposition, Atmos. Chem. Phys., 12, 591-603, doi:10.5194/acp-12-591-2012, 2012.

Andreae, M. O., Andreae, T. W., Talbot, R. W., and Harriss, R. C.: Formic and acetic acid over the central Amazon region, Brazil. I. Dry season, J. Geophys. Res., 93, 1616-1624, doi:10.1029/JD093iD02p01616, 1988.

Andrews, D. U., Heazlewood, B. R., Maccarone, A. T., Conroy, T., Payne, R. J., Jordan, M. J. T., and Kable, S. H.: Phototautomerization of Acetaldehyde to Vinyl Alcohol: A Potential Route to Tropospheric Acids Science, 337, 1203-1206, 2012.

Archibald, A. T., McGillen, M. R., Taatjes, C. A., Percival, C. J., and Shallcross, D. E.: Atmospheric Transformation of Enols: A Potential Secondary Source of Carboxylic Acids in the Urban Troposphere, Geophys. Res. Lett., 34, L21801, doi:10.1029/2007GL031032, 2007.

Beer, R., Glavich, T. A., and Rider, D. M.: Tropospheric emission spectrometer for the Earth Observing System's Aura satellite, Appl. Optics, 40, 2356-2367, 2001.

Bohn, B., Siese, M., and Zetzschn, C.: Kinetics of the $\mathrm{OH}+\mathrm{C} 2 \mathrm{H} 2$ reaction in the presence of $\mathrm{O}_{2}$, J. Chem. Soc., Faraday Trans., 92, 1459-1466, 1996.

Bowman, K. W., Rodgers, C. D., Sund-Kulawik, S., Worden, J., Sarkissian, E., Osterman, G., Steck, T., Luo, M., Elder- ing, A., Shephard, M. W., Worden, H., Clough, S. A., Brown, P. D., Rinsland, C. P., Lampel, M., Gunson, M., and Beer, R.: Tropospheric emission spectrometer: Retrieval method and error analysis, IEEE Geosci. Remote Sens., 44, 1297-1307, doi:10.1109/TGRS.2006.871234, 2006.

Cady-Pereira, K. E., Shephard, M. W., Millet, D. B., Luo, M., Wells, K. C., Xiao, Y., Payne, V. H., and Worden, J.: Methanol from TES global observations: retrieval algorithm and seasonal and spatial variability, Atmos. Chem. Phys., 12, 8189-8203, doi:10.5194/acp-12-8189-2012, 2012.

Chaliyakunnel, S., Dylan, B., Millet, K. C., Wells, K. E., CadyPereira, M. W., Shephard, M., Luo, M., and Paulot, F.: Global tropospheric formic acid measurements from the TES satellite sensor: retrieval evaluation and the importance of biogenic and pyrogenic sources, in preparation, 2014.

Clough, S. A., Shephard, M. W., Mlawer, E. J., Delamere, J. S., Iacono, M. J., Cady-Pereira, K., Boukabara, S., and Brown, R. D.: Atmospheric radiative transfer modeling: a summary of the AER codes, J. Quant. Spectrosc. Ra., 91, 233-244, 2005.

Clubb, A. E., Jordan, M. J. T., Kable, S. H., and Osborn, D. L.: Phototautomerization of Acetaldehyde to Vinyl Alcohol: A Primary Process in UV-Irradiated Acetaldehyde from 295 to $335 \mathrm{~nm}$, J. Phys. Chem. Lett., 3, 3522-3526, 2012.

Coheur, P.-F., Clarisse, L., Turquety, S., Hurtmans, D., and Clerbaux, C.: IASI measurements of reactive trace species in biomass burning plumes, Atmos. Chem. Phys., 9, 5655-5667, doi:10.5194/acp-9-5655-2009, 2009.

Connor, T. C., Shephard, M. W., Payne, V. H., Cady-Pereira, K. E., Kulawik, S. S., Luo, M., Osterman, G., and Lampel, M.: Long-term stability of TES satellite radiance measurements, Atmos. Meas. Tech., 4, 1481-1490, doi:10.5194/amt-4-1481-2011, 2011.

da Silva, G.: Carboxylic acid catalyzed keto-enol tautomerizations in the gas phase, Angew. Chem., 122, 7685-7687, 2010.

Goode, J. G., Yokelson, R. J., Ward, D. E., Susott, R. A., Babbitt, R. E., Davies, M. A., and Hao, W. M.: Measurements of excess $\mathrm{O}_{3}, \mathrm{CO}_{2}, \mathrm{CO}, \mathrm{CH}_{4}, \mathrm{C}_{2} \mathrm{H}_{4}, \mathrm{C}_{2} \mathrm{H}_{2}, \mathrm{HCN}, \mathrm{NO}, \mathrm{NH}_{3}$, $\mathrm{HCOOH}, \mathrm{CH}_{3} \mathrm{COOH}, \mathrm{HCHO}$, and $\mathrm{CH}_{3} \mathrm{OH}$ in 1997 Alaskan biomass burning plumes by airborne fouriertransform infrared spectroscopy (AFTIR), J. Geophys. Res., 105, 22147-22166, 2000.

Grutter, M., Glatthor, N., Stiller, G. P., Fischer, H., Grabowski, U., Höpfner, M., Kellmann, S., Linden, A., and von Clarmann, T.: Global distribution and variability of formic acid as observed by MIPAS-ENVISAT, J. Geophys. Res., 115, D10303, doi:10.1029/2009JD012980, 2010.

Guenther, A. B., Jiang, X., Heald, C. L., Sakulyanontvittaya, T., Duhl, T., Emmons, L. K., and Wang, X.: The Model of Emissions of Gases and Aerosols from Nature version 2.1 (MEGAN2.1): an extended and updated framework for modeling biogenic emissions, Geosci. Model Dev., 5, 1471-1492, doi:10.5194/gmd-51471-2012, 2012.

Hatch, C. D., Gough, R. V., and Tolbert, M. A.: Heterogeneous uptake of the $\mathrm{C} 1$ to $\mathrm{C} 4$ organic acids on a swelling clay mineral, Atmos. Chem. Phys., 7, 4445-4458, doi:10.5194/acp-7-4445-2007, 2007.

Hatakeyama, S., Washida, N., and Akimoto, H.: Rate constants and mechanisms for the reaction of hydroxyl (OD) radicals with 
acetylene, propyne, and 2-butyne in air at $297 \pm 2 \mathrm{~K}$, J. Phys. Chem., 6, 173-178, 1986.

Jacob, D. J.: Chemistry of $\mathrm{OH}$ in remote clouds and its role in the production of formic acid and peroxymonosulfate, J. Geophys. Res., 91, 9807-9826, doi:10.1029/JD091iD09p09807, 1986.

Jacob, D. J., Crawford, J. H., Maring, H., Clarke, A. D., Dibb, J. E., Emmons, L. K., Ferrare, R. A., Hostetler, C. A., Russell, P. B., Singh, H. B., Thompson, A. M., Shaw, G. E., McCauley, E., Pederson, J. R., and Fisher, J. A.: The Arctic Research of the Composition of the Troposphere from Aircraft and Satellites (ARCTAS) mission: design, execution, and first results, Atmos. Chem. Phys., 10, 5191-5212, doi:10.5194/acp-10-5191-2010, 2010.

Jardine, K., Yañez Serrano, A., Arneth, A., Abrell, L., Jardine, A., Artaxo, P., Alves, E., Kesselmeier, J., Taylor, T., Saleska, S., and Huxman, T.: Ecosystem-scale compensation points of formic and acetic acid in the central Amazon, Biogeosciences, 8, 37093720, doi:10.5194/bg-8-3709-2011, 2011.

JPL: TES Level 2 Data User's Guide, edited by: Osterman, G., 2006.

Karton, A.: Inorganic acid-catalyzed tautomerization of vinyl alcohol to acetaldehyde, Chem. Phys. Lett., 592, 330-333, 2014.

Kawamura, K., Ng, L. L., and Kaplan, I. R.: Determination of organic acids (C1-C10) in the atmosphere, motor exhausts, and engine oils, Environ. Sci. Technol., 19, 1082-1086, 1985, 1985.

Keene, W. C. and Galloway, J. N.: The biogeochemical cycling offormic and acetic acids through the troposphere: An overview of current understanding, Tellus B, 40, 322-334, 1988.

Kesselmeier, J., Bode, K., Gerlach, C., and Jork, E. M.: Exchange of atmospheric formic and acetic acids with trees and crop plants under controlled chamber and purified air conditions, Atmos. Environ., 32, 1765-1775, 1998.

Kuhn, U., Rottenberger, S., Biesenthal, T., Ammann, C., Wolf, A., Schebeske, G., Oliva, S. T., Tavares, T. M., and Kesselmeier, J.: Exchange of short-chain monocarboxylic acids by vegetation at a remote tropical forest site in Amazonia, J. Geophys. Res., 107, 8069, doi:10.1029/2000JD000303, 2002.

Kulawik, S. S., Worden, J., Eldering, A., Bowman, K., Gunson, M., Osterman, G. B., Zhang, L., Clough, S., Shephard, M. W., and Beer, R.: Implementation of cloud retrievals for Tropospheric Emission Spectrometer (TES) atmospheric retrievals: part 1. Description and characterization of errors on trace gas retrievals, J. Geophys. Res., 111, D24204, doi:10.1029/2005JD006733, 2006.

Lawrence, D. M., Oleson, K. W., Flanner, M. G., Thornton, P. E., Swenson, S. C., Lawrence, P. J., Zeng, X., Yang, Z.-L., Levis, S., Sakaguchi, K., Bonan, G. B., and Slater, A. G.: Parameterization improvements and functional and structural advances in version 4 of the Community Land Model, J. Adv. Model. Earth Sys., 3, M03001, doi:10.1029/2011MS000045, 2011.

Lee, A., Goldstein, A. H., Kroll, J. H., Ng, N. L., Varutbangkul, V., Flagan, R. C., and Seinfeld, J. H.: Gas-phase products and secondary aerosol yields from the photooxidation of 16 different terpenes, J. Geophys. Res., 111, D17305, doi:10.1029/2006JD007050, 2006.

Mlawer, E. J., Payne, V. H., Moncet, J.-L., Delamere, J. S., Alvarado, M. J., and Tobin, D. C.: Development and recent evaluation of the MT_CKD model of continuum absorption, Philos. T. Roy. Soc. A, 370, 1-37, doi:10.1098/rsta.2011.0295, 2012.
Moncet, J.-L., Uymin, G., Lipton, A. E., and Snell, H. E.: Infrared radiance modeling by optimal spectral sampling, J. Atmos. Sci., 65, 3917-3934, 2008.

Neeb, P., Sauer, F., Horie, O., and Moortgat, G. K.: Formation of hydroxymethyl hydroperoxide and formic acid in alkene ozonolysis in the presence of water vapour, Atmos. Environ., 31, 14171423, 1997.

Ngwabie, N. M., Schade, G. W., Custer, T. G., Linke, S., and Hinz, T.: Abundances and flux estimates of volatile organic compounds from a dairy cowshed in Germany, J. Environ. Qual., 37, 565573, 2008.

Payne, V. H., Clough, S. A., Shephard, M. W., Nassar, R., and Logan, J. A.: Information-centered representation of retrievals with limited degrees of freedom for signal: Application to methane from the Tropospheric Emission Spectrometer, J. Geophys. Res., 114, D10307, doi:10.1029/2008JD010155, 2009.

Payne, V. H., Alvarado, M. J., Cady-Pereira, K. E., Worden, J. R., Kulawik, S. S., and Fischer, E. V.: Satellite observations of peroxyacetyl nitrate from the Aura Tropospheric Emission Spectrometer, Atmos. Meas. Tech. Discuss., 7, 5347-5379, doi:10.5194/amtd-7-5347-2014, 2014.

Paulot, F., Wunch, D., Crounse, J. D., Toon, G. C., Millet, D. B., DeCarlo, P. F., Vigouroux, C., Deutscher, N. M., González Abad, G., Notholt, J., Warneke, T., Hannigan, J. W., Warneke, C., de Gouw, J. A., Dunlea, E. J., De Mazière, M., Griffith, D W. T., Bernath, P., Jimenez, J. L., and Wennberg, P. O.: Importance of secondary sources in the atmospheric budgets of formic and acetic acids, Atmos. Chem. Phys., 11, 1989-2013, doi:10.5194/acp-11-1989-2011, 2011.

Pinder, R. W., Walker, J. T., Bash, J. O., Cady-Pereira, K. E., Henze, D. K., Luo, M., and Shephard, M. W.: Quantifying spatial and temporal variability in atmospheric ammonia with in situ and space-based observations, Geophys. Res. Lett., 38, L04802, doi:10.1029/2010GL046146, 2011.

Razavi, A., Karagulian, F., Clarisse, L., Hurtmans, D., Coheur, P. F., Clerbaux, C., Müller, J. F., and Stavrakou, T.: Global distributions of methanol and formic acid retrieved for the first time from the IASI/MetOp thermal infrared sounder, Atmos. Chem. Phys., 11, 857-872, doi:10.5194/acp-11-857-2011, 2011.

Rinsland, C. P., Boone, C. D., Bernath, P. F., Mahieu, E., Zander, R., Dufour, G., Clerbaux, C., Turquety, S., Chiou, L., Mc-Connell, J. C., Neary, L., and Kaminski, J. W.: Atmospheric Chemistry Experiment austral spring 2004 and 2005 Southern Hemisphere tropical-mid-latitude upper tropospheric measurements, Geophys. Res. Lett, 33, L23804, doi:10.1029/2006GL027128, 2006.

Rinsland, C. P., Dufour, G., Boone, C. D., Bernath, P. F., Chiou, L., Coheur, P.-F., Turquety, S., and Clerbaux, C.: Satellite boreal measurements over Alaska and Canada during JuneJuly 2004: Simultaneous measurements of upper tropospheric $\mathrm{CO}, \mathrm{C}_{2} \mathrm{H}_{6}, \mathrm{HCN}, \mathrm{CH}_{3} \mathrm{Cl}, \mathrm{CH}_{4}, \mathrm{C}_{2} \mathrm{H}_{2}, \mathrm{CH}_{3} \mathrm{OH}, \mathrm{HCOOH}, \mathrm{OCS}$, and $\mathrm{SF}_{6}$ mixing ratios, Global Biogeochem. Cy., 21, B3008, doi:10.1029/2006GB002795, 2007.

Rodgers, C. D.: Inverse methods for atmospheric Sounding: Theory and Practice, World Sci., Hackensack, N. J., 2000.

Rothman, L. S., Jacquemart, D., Barbe, A., Benner, D. C., Birk, M., Brown, L. R., Carleer, M. R., Chackerian Jr., C., Chance, K., Coudert, L. H., Dana, V., Devi, V. M., Flaud, J.-M., Gamache, R. R., Goldman, A., Hartmann, J.-M., Jucks, K. W., Maki, A. G., 
Mandin, J.-Y., Massie, S. T., Orphal, J., Perrin, A., Rinsland, C. P., Smith, M. A. H., Tennyson, J., Tolchenov, R. N., Toth, R. A., Vander Auwera, J., Varanasi, P., and Wagner, G.: The HITRAN 2004 molecular spectroscopic database, J. Quant. Spectrosc. Ra., 96, 139-204, 2005.

Rothman, L. S., Gordon, I. E., Barbe, A., Benner, D. C., Bernath, P. F., Birk, M., Boudon, V., Brown, L. R., Campargue, A., Champion, J.-P., Chance, K., Coudert, L. H., Dana, V., Devi, V. M., Fally, S., Flaud, J.-M., Gamache, R. R., Goldman, A., Jacquemart, D., Kleiner, I., Lacome, N., Lafferty, W. J., Mandin, J.Y., Massie, S. T., Mikhailenko, S. N., Miller, C. E., MoazzenAhmadi, N., Naumenko, O. V., Nikitin, A. V., Orphal, J., Perevalov, V. I., Perrin, A., Predoi-Cross, A., Rinsland, C. P., Rotger, M., Šimecková, M., Smith, M. A. H., Sung, K., Tashkun, S. A., Tennyson, J., Toth, R. A., Vandaele, A. C., and Vander Auwera, J.: The HITRAN 2008 molecular spectroscopic database, J. Quant. Spectrosc. Ra., 110, 533-572, 2009.

Sanhueza, E. and Andreae, M. O.: Emission of formic and acetic acids from tropical savanna soils, Geophys. Res. Lett., 18, 17071710, 1991.

Shephard, M. W., Worden, H. M., Cady-Pereira, K. E., Lampel, M., Luo, M., Bowman, K. W., Sarkissian, E., Beer, R., Rider, D. M., Tobin, D. C., Revercomb, H. E., Fisher, B. M., Tremblay, D., Clough, S. A., Osterman, G. B., and Gunson, M.: Tropospheric Emission Spectrometer Spectral Radiance Comparisons, J. Geophys. Res., 113, D15S05, doi:10.1029/2007JD008856, 2008.

Shephard, M. W., Clough, S. A., Payne, V. H., Smith, W. L., Kireev, S., and Cady-Pereira, K. E.: Performance of the line-by-line radiative transfer model (LBLRTM) for temperature and species retrievals: IASI case studies from JAIVEx, Atmos. Chem. Phys., 9, 7397-7417, doi:10.5194/acp-9-7397-2009, 2009.

Shephard, M. W., Cady-Pereira, K. E., Luo, M., Henze, D. K., Pinder, R. W., Walker, J. T., Rinsland, C. P., Bash, J. O., Zhu, L., Payne, V. H., and Clarisse, L.: TES ammonia retrieval strategy and global observations of the spatial and seasonal variability of ammonia, Atmos. Chem. Phys., 11, 10743-10763, doi:10.5194/acp-11-10743-2011, 2011.

So, S., Wille, U., and da Silva, G.: Atmospheric chemistry of enols: A theoretical study of the vinayl alcohol $+\mathrm{OH}+\mathrm{O}_{2}$ reaction mechanism, Environ. Sci. Technol., 48, 6694-6701, doi:10.1021/es500319q, 2014.

Stavrakou, T., Müller, J.-F., Peeters, J., Razavi, A., Clarisse, L., Clerbaux, C., Coheur, P.-F., Hurtmans, D., De Mazière, M., Vigouroux, C., Deutscher, N. M., Griffith, D. W. T., Jones, N., and Paton-Walsh, C.: Satellite evidence for a large source of formic acid from boreal and tropical forests, Nat. Geosci., 5, 2630, doi:10.1038/ngeo1354, 2012.
Talbot, R. W., Beecher, K. M., Harriss, R. C., and Cofer, W. R.: Atmospheric geochemistry of formic and acetic acids at a midlatitude temperate site, J. Geophys. Res., 93, 1638-1652, 1988.

Vander Auwera, J., Didriche, K., Perrin, A., and Keller, F.: Absolute line intensities for formic acid and dissociation constant of the Dimer, J. Chem. Phys., 126, 124311, doi:10.1063/1.2712439, 2007.

van der Werf, G. R., Randerson, J. T., Giglio, L., Collatz, G. J., Mu, M., Kasibhatla, P. S., Morton, D. C., DeFries, R. S., Jin, Y., and van Leeuwen, T. T.: Global fire emissions and the contribution of deforestation, savanna, forest, agricultural, and peat fires (19972009), Atmos. Chem. Phys., 10, 11707-11735, doi:10.5194/acp10-11707-2010, 2010.

Wells, K. C., Millet, D. B., Hu, L., Cady-Pereira, K. E., Xiao, Y., Shephard, M. W., Clerbaux, C. L., Clarisse, L., Coheur, P.F., Apel, E. C., de Gouw, J., Warneke, C., Singh, H. B., Goldstein, A. H., and Sive, B. C.: Tropospheric methanol observations from space: retrieval evaluation and constraints on the seasonality of biogenic emissions, Atmos. Chem. Phys., 12, 5897-5912, doi:10.5194/acp-12-5897-2012, 2012.

Wells, K. C., Millet, D. B., Cady-Pereira, K. E., Shephard, M. W., Henze, D. K., Bousserez, N., Apel, E. C., de Gouw, J., Warneke, C., and Singh, H. B.: Quantifying global terrestrial methanol emissions using observations from the TES satellite sensor, Atmos. Chem. Phys., 14, 2555-2570, doi:10.5194/acp-14-25552014, 2014.

Wesely, M. L.: Parameterization of surface resistance to gaseous dry deposition in regional-scale numerical models, Atmos. Environ., 23, 1293-1304, 1989.

Worden, J., Kulawik, S. S., Shephard, M. W., Clough, S. A., Worden, H., Bowman, K., and Goldman, A.: Predicted errors of tropospheric emission spectrometer nadir retrievals from spectral window selection, J. Geophys. Res., 109, D09308, doi:10.1029/2004JD004522, 2004.

Zhu, L., Henze, D. K., Cady-Pereira, K. E., Shephard, M. W., Luo, M., Pinder, R. W., Bash, J. O., and Jeong, G.-R.: Constraining U.S. ammonia emissions using TES remote sensing observations and the GEOS-Chem adjoint mode, J. Geophys. Res., 118, 33553368, doi:10.1002/jgrd.50166, 2013. 